\title{
Insect immunology and hematopoiesis
}

Julián F. Hillyer

Department of Biological Sciences, Vanderbilt University, Nashville, TN 37235

Contact information:

Julián F. Hillyer

Department of Biological Sciences

Vanderbilt University

VU Station B 35-1634

Nashville, TN 37235, U.S.A.

Tel. 615-343-2065

Fax. 615-343-6707

Email: julian.hillyer@vanderbilt.edu 


\section{Abstract:}

Insects combat infection by mounting powerful immune responses that are mediated by hemocytes, the fat body, the midgut, the salivary glands and other tissues. Foreign organisms that have entered the body of an insect are recognized by the immune system when pathogenassociated molecular patterns bind host-derived pattern recognition receptors. This, in turn, activates immune signaling pathways that amplify the immune response, induce the production of factors with antimicrobial activity, and activate effector pathways. Among the immune signaling pathways are the Toll, Imd, Jak/Stat, JNK, and insulin pathways. Activation of these and other pathways leads to pathogen killing via phagocytosis, melanization, cellular encapsulation, nodulation, lysis, RNAi-mediated virus destruction, autophagy and apoptosis. This review details these and other aspects of immunity in insects, and discusses how the immune and circulatory systems have co-adapted to combat infection, how hemocyte replication and differentiation takes place (hematopoiesis), how an infection prepares an insect for a subsequent infection (immune priming), how environmental factors such as temperature and the age of the insect impact the immune response, and how social immunity protects entire groups. Finally, this review highlights some underexplored areas in the field of insect immunobiology.

\section{Keywords:}

Insecta; pattern recognition receptor; immune signaling; hemocyte; pathogen; immunity 


\section{Introduction}

Insects interact with a wide array of pathogens. Many of these pathogens seek to invade and colonize the insects they come in contact with, and in many cases, successful colonization leads to detrimental effects to the host. A diversity of pathogenic organisms can infect insects, including viruses, bacteria, fungi, protozoans, nematodes, and even other insects (Mahy, 2004; Pennacchio and Strand, 2006; Vega and Kaya, 2012). Some of these interactions are general whereas others are highly specific. For example, the fungus Beauveria bassiana is a facultative pathogen that infects insects from numerous taxonomic orders whereas the Plasmodium sp. that cause human malaria are obligate pathogens that only infect - and are only transmitted by - select species of anopheline mosquitoes (Manguin et al., 2008; OrtizUrquiza et al., 2015).

To reduce the probability of infection, insects have evolved physical barriers that keep pathogens from entering their main body cavity, or hemocoel. The most encompassing physical barrier that prevents the entry of pathogens is the cuticle (Lundgren and Jurat-Fuentes, 2012; Siva-Jothy et al., 2005). This chitinous, hydrophobic material forms the exoskeleton of the insect, and also lines the foregut, the hindgut, and the tracheal system. Pathogens that enter the body through the cuticle do so through natural wounds, or by the enzymatic digestion of this material. Pathogens also enter the body via ingestion. Following ingestion, pathogens are immediately subjected to antagonistic barriers, such as cibarial or pharyingial armatures, enzymes of the digestive system, inhospitable $\mathrm{pH}$, and the endogenous microbiota (Cirimotich et al., 2011; Lundgren and Jurat-Fuentes, 2012; McGreevy et al., 1978; Siva-Jothy et al., 2005). Ingested pathogens that seek to exit the digestive tract and gain entry into the hemocoel must also traverse the cellular epithelium of the midgut, and in some cases, a non-cellular and chitinous peritrophic matrix (Kato et al., 2008; Kuraishi et al., 2011; Weiss et al., 2014).

Although entering the hemocoel is a formidable enterprise, many organisms have evolved mechanisms to efficiently accomplish this. Some fungi enter the hemocoel by 
enzymatically degrading the cuticle (Pedrini et al., 2007), and pathogens that are routinely ingested have evolved innovative strategies to exit this intestinal compartment. For example, the bacterium, Bacillus thuringiensis, produces Cry toxins that destroy the epithelial cells of the digestive tract, the protozoan parasites that cause malaria utilize their apical complex to penetrate the cells of the midgut, and filarial nematodes physically burrow out of the intestinal space (Christensen and Sutherland, 1984; Roberts et al., 2013; Vachon et al., 2012). Some pathogens elect to not leave the gut. For example, Trypanosoma cruzi and Yersinia pestis, which in humans cause Chagas' disease and plague, respectively, remain within the digestive tract of their kissing bug and flea hosts (Roberts et al., 2013).

Pathogens that come to reside in the midgut, the hemocoel or the internal organs, elicit immune responses that have evolved to eliminate or control infections. These immune responses range from cellular events such as phagocytosis, to humoral events that include lysis and melanization. This review presents an overview of these and other immune processes, and how the primary immune cells of insects, the hemocytes, are produced and replenished.

\section{Anatomy of the insect immune system}

Once pathogens gain entry into the body of an insect they come to reside in the midgut, the hemocoel, or other cells and organs. The recognition of pathogens as both foreign and dangerous induces immune responses that are driven by multiple types of immune cells and tissues (Figure 1).

The primary immune cells in insects are the hemocytes (Hillyer and Strand, 2014; Strand, 2008). These cells, which are present in the hemocoel, drive cellular immune processes such as phagocytosis, and produce humoral immune factors that lead to pathogen killing via lysis or melanization. Hemocyte populations can be divided using two, non-exclusive criteria: their spatial state and their functional properties. From a spatial perspective, hemocytes either circulate with the hemolymph, in which case they are called circulating hemocytes, or are 
attached to tissues, in which case they are called sessile hemocytes (Hillyer and Strand, 2014; Strand, 2008). The distinction between circulating and sessile hemocytes is strictly spatial, and sessile hemocytes can release from their point of attachment and enter circulation, and circulating hemocytes can attach to tissues and become sessile (Babcock et al., 2008; King and Hillyer, 2012; Markus et al., 2009; Sigle and Hillyer, 2016). From a functional perspective, most insects have several sub-populations of hemocytes that are morphologically and functionally distinct, but the nomenclature for these cell populations is not normalized across Insecta. For example, lepidopteran larvae contain four distinct types of hemocytes: plasmatocytes that are involved in capsule formation, granulocytes that drive phagocytosis, oenocytoids that produce enzymes involved in the melanization cascade (e.g., phenoloxidase), and spherule cells whose immune function remains unclear (Lavine and Strand, 2002; Strand, 2008). Mosquitoes, on the other hand, have phagocytic granulocytes, phenoloxidase-producing oenocytoids, and prohemocytes (Castillo et al., 2006; Hillyer et al., 2003a; Hillyer and Strand, 2014). As a final example, the fruit fly, Drosophila melanogaster, has phagocytic plasmatocytes, phenoloxidaseproducing crystal cells, and encapsulating lamellocytes (Honti et al., 2014).

The fat body, the midgut and the salivary glands are also important drivers of the insect immune response. The fat body, which is composed of loosely associated cells that are rich in lipids and glycogen, lines the integument of the hemocoel (Costa-Leonardo et al., 2013; Larsen, 1976; Martins et al., 2011). Besides functioning in energy storage and the synthesis of the vitellogenin precursors required for the production of eggs, the fat body produces and secretes antimicrobial peptides with lytic activity as well as additional components of the humoral immune response (Aggarwal and Silverman, 2008; Hillyer, 2010; Wang et al., 2014a). The midgut, an organ that primarily functions in digestion and absorption of nutrients, extends almost the entire length of the abdomen and produces nitric oxide synthase and other lytic factors that kill pathogens that are either in the lumen of the gut or are attempting to enter the hemocoel by traversing this epithelium (Buchon et al., 2009; Gupta et al., 2009; Lehane et al., 1997; Lim et 
al., 2005; Luckhart et al., 1998). The salivary glands, an organ primarily involved in the initial stages of feeding, are usually located in the anterior of the thorax and produce factors that impact the viability of infecting microorganisms (Ferrandon et al., 1998; Pinto et al., 2008).

These immune tissues, although physically and morphologically independent, interact during the course of an infection. For example, factors produced by the fat body induce immune activity in hemocytes (Schmid et al., 2014). Conversely, hemocyte-produced factors are required for immune activity in the fat body (Brennan et al., 2007; Shia et al., 2009). Humoral immune factors that are produced by hemocytes are also transported to the gut where they exert their lytic and melanizing activity (Fraiture et al., 2009), and midgut-produced factors can activate immune activity in the fat body (Wu et al., 2012).

\section{Pathogen recognition}

The initiation of an immune response requires that the insect recognize an invading agent. During an infection, such recognition usually occurs when pathogen-associated molecular patterns (PAMPs, also known as microbe-associated molecular patterns or MAMPs) bind to host-derived pattern recognition receptors (PPRs). PRRs recognize conserved motifs that are present in microbes but are absent in insects. Examples of PAMPs are bacterial peptidoglycans and fungal $\beta-1,3$ glucans.

PRRs are conceptually divided into evolutionarily conserved protein families. These protein families exhibit remarkable diversity, which is likely a consequence of the drastic differences in the ecology of members of the class Insecta. Among the different classes of PRRs are the peptidoglycan recognition proteins (PGRP), the immunoglobulin domain proteins, the fibrinogen-related proteins (FREP), the thioester-containing proteins, the $\beta-1,3$ glucan recognition proteins (also known as the Gram(-) binding proteins), the galectins, the C-type lectins, the leucine-rich repeat containing proteins (LRR), down syndrome cell adhesion molecule (DSCAM), and the Nimrod proteins (Das et al., 2009; Palmer and Jiggins, 2015; 
Zhang et al., 2015). Many PRR protein families have expanded or contracted in different taxa (Figure 2). For example, there are 7, 8, 13, 6, 14, 4, 4, and 2 members of the PGRP protein family in Anopheles gambiae, Aedes aegypti, Drosophila melanogaster, Tribolium castaneum, Manduca sexta, Apis mellifera, Bombus terrestris, and Megachile rotundata, respectively (Barribeau et al., 2015; Evans et al., 2006; Waterhouse et al., 2007; Zhang et al., 2015), and the genome of the pea aphid, Acyrthosiphon pisum, does not encode any PGRPs (Gerardo et al., 2010).

Along with the genetic diversity of PRRs, their activity varies widely. For example, some members of the Nimrod gene family encode cell surface receptors with multiple transmembrane domains whereas others encode secreted proteins, and different members of this same protein family also recognize different combinations of pathogens (Estevez-Lao and Hillyer, 2014; Kocks et al., 2005; Kurucz et al., 2007; Zsamboki et al., 2013). Furthermore, some PRRs directly elicit immune effector processes such as phagocytosis and melanization, others activate intracellular signaling pathways that activate the transcription of immune effector genes, and yet others activate both effector and signaling pathways (Choe et al., 2002; Levashina et al., 2001). Finally, some proteins that are often considered PRRs, such as members of the LRR protein family, may not directly interact with PAMPs. Instead they regulate immune responses via the direct interaction with other host proteins (Fraiture et al., 2009).

\section{Immune signaling}

Pathogen recognition induces the activation of signal transduction pathways that (1) amplify immune responses, (2) induce the production of factors with antimicrobial activity, and (3) potentiate effector mechanisms. The three most characterized immune signaling pathways in insects are the Toll pathway, the Imd pathway, and the Jak/Stat pathway (Figures 2, 3).

The Toll pathway is an evolutionarily conserved signaling pathway that, in insects, functions in both development and immunity (Cao et al., 2015; Clayton et al., 2014; Evans et al., 
2006; Kingsolver et al., 2013; Lemaitre and Hoffmann, 2007; Lindsay and Wasserman, 2014; Sim et al., 2014; Xu and Cherry, 2014). In the realm of immunity, the Toll pathway is initiated when PRRs activate the extracellular cytokine, Spätzle, which binds the cellular receptor Toll, leading to intracellular events involving Myd88, Pelle, Tube, and others. This signal transduction results in the nuclear translocation of NF-KB transcription factors (e.g., Dif/Dorsal and Rel1), which activate the transcription of antimicrobial peptides and other immune effector genes. The Toll pathway is primarily effective in combating Gram(+) bacteria, viruses, fungi, and in the case of mosquitoes, some plasmodia (Plasmodium berghel).

In a conceptually similar manner, the Imd pathway is activated when a PAMP binds the extracellular receptor PGPR-LC (Cao et al., 2015; Clayton et al., 2014; Evans et al., 2006; Kingsolver et al., 2013; Kleino and Silverman, 2014; Lemaitre and Hoffmann, 2007; Sim et al., 2014; Xu and Cherry, 2014). This induces intracellular signaling via Imd, Fadd, Dredd, and others, which leads to the nuclear translocation of NF-KB transcription factors (e.g., Relish and Rel2) and the transcriptional activation of antimicrobial peptides and other immune effector genes. This immune pathway is primarily effective in combating Gram(-) bacteria, viruses, and in the case of mosquitoes, some plasmodia (Plasmodium falciparum).

Similar to the Toll pathway, the Jak/Stat pathway is involved in both development and immunity (Cao et al., 2015; Clayton et al., 2014; Evans et al., 2006; Kingsolver et al., 2013; Myllymaki and Ramet, 2014; Sim et al., 2014; Xu and Cherry, 2014). During an infection, the Jak/Stat pathway becomes activated when the extracellular cytokine Unpaired (Upd) binds the cellular receptor Domeless (Dome). Domeless is phosphorylated by Hopscotch (Hop), which recruits Stat. Stat then dimerizes and is translocated to the nucleus, and this activates the transcription of antimicrobial genes such as nitric oxide synthase. The Jak/Stat pathway is involved in the antibacterial, antiviral, and in the case of mosquitoes, the anti-Plasmodium response. 
The Toll, Imd and Jak/Stat pathways are tightly regulated. Their activation is initiated by the binding of PAMPs by PRRs, but intracellular negative regulators function to keep these pathways in check. Specifically, Cactus, Caspar, and Socs/Pias are intracellular signaling molecules that negatively regulate, or repress, the Toll, Imd and Jak/Stat pathways, respectively (Clayton et al., 2014; Kleino and Silverman, 2014; Lindsay and Wasserman, 2014; Myllymaki and Ramet, 2014).

Other signal transduction pathways are also involved in immunity but have received less attention. For example, components of the Imd pathway can activate the JNK pathway, which leads to, among other things, the transcriptional activation of antimicrobial genes (Boutros et al., 2002; Wojda et al., 2004). Also, the insulin/insulin growth factor-1 signaling pathway is involved in the anti-Plasmodium response of mosquitoes (Pakpour et al., 2014), and RNA interference pathways (RNAi), which are discussed in greater detail in section 5.5, are essential components of the antiviral response. These pathways, although highly conserved, are not present in all insects. For example, three hemimetabolous insects - the pea aphid, the body louse, and the kissing bug - lack specific components of the IMD pathway, such as Imd and Fadd (Gerardo et al., 2010; Kim et al., 2011; Mesquita et al., 2015). Interestingly, although neither Imd, Fadd, Dredd, Caspar, Ird5 nor Kenny are encoded in the genome of the kissing bug, Rhodnius prolixus, the Imd pathway of this insect remains active and inducible (Mesquita et al., 2015).

\section{Immune effector mechanisms}

Pathogen death is accomplished via multiple effector mechanisms that can be broadly divided into phagocytosis, melanization, encapsulation, nodulation, lysis, RNAi-mediated virus destruction, autophagy, and apoptosis (Figure 4). These mechanisms are not mutually exclusive. For example, (1) pathogens that have been melanized in the hemocoel are often phagocytosed (Hillyer et al., 2003a, b), (2) lytic and melanizing components can be present on the surface of the same pathogens (Hillyer and Christensen, 2005), (3) lysed pathogens are at 
times melanized (Osta et al., 2004; Volz et al., 2006), and (4) encapsulation and nodulation in most cases involves the aggregation of hemocytes and melanization (Pech and Strand, 1996; Ratcliffe and Gagen, 1977).

\subsection{Phagocytosis}

Phagocytosis is an evolutionarily conserved cellular immune process that is used by both vertebrate and invertebrate animals for the destruction of small foreign organisms. Phagocytosis is initiated when a foreign object is recognized and bound by proteins in the plasma membrane of the phagocyte. The foreign object is then internalized into a membranedelimited phagosome, the phagosome fuses with a lysosome, and hydrolytic enzymes digest the particle. From a spatial perspective, phagocytosis is carried out by both circulating and sessile hemocytes (Hillyer and Strand, 2014). From a functional perspective, the hemocytes that phagocytose pathogens are the granulocytes of Lepidoptera, Hemiptera and mosquitoes, and the plasmatocytes of fruit flies (Hillyer et al., 2003a, b; Hillyer and Strand, 2014; Honti et al., 2014; Laughton et al., 2011; Strand, 2008). As a percentage of the overall hemocyte population, the majority of hemocytes are phagocytic.

Phagocytosis is a rapid response. In mosquitoes, circulating and sessile hemocytes begin to phagocytose pathogens within seconds of their introduction (Hillyer et al., 2003b; King and Hillyer, 2012; Sigle and Hillyer, 2016). In mosquitoes and the tobacco hornworm, some hemocytes can phagocytose hundreds of bacteria at any given time (Dean et al., 2004; Hillyer et al., 2005). Furthermore, unlike melanization, which produces melanotic capsules that remain in the hemocoel for the lifetime of the insect, phagocytosis is a renewable response whereby hemocytes repeatedly internalize and degrade pathogens. Perhaps for this reason smaller arthropods rely more heavily on phagocytosis than larger ones for the killing of small foreign organisms (Oliver et al., 2011). It is also likely that, in a manner similar to what occurs in 
vertebrates, the process of phagocytosis activates other components of the insect immune response.

Phagocytosis is initiated when a cell-surface PRR or a humoral PRR binds a PAMP. PRRs that have been empirically shown to be involved in phagocytosis include thioestercontaining proteins, Nimrod proteins, DSCAM, $\beta$-integrins, and PGRPs (Dong et al., 2006; Kurucz et al., 2007; Levashina et al., 2001; Mamali et al., 2009; Ramet et al., 2002). Different PRRs have different specificities. For example, D. melanogaster PGRP-LC mediates the phagocytosis of E. coli but not $S$. aureus (Ramet et al., 2002), and NimC1 mediates the phagocytosis of $S$. aureus and to a lesser extent $E$. coli (Kurucz et al., 2007). The intracellular signaling pathways that drive or enhance phagocytosis remain poorly understood, but in mosquitoes the cell death abnormal 2 (CED2)/CED5 and CED6 pathways regulate the internalization of bacteria. Specifically, the CED6 pathways drives phagocytosis that is mediated by TEP1, TEP3, LRIM1 and LRP1, whereas the CED2/CED5 pathway drives phagocytosis that is initiated by TEP4 and BINT2 (Moita et al., 2005).

\subsection{Melanization}

Melanization is an enzymatic process used by insects for cuticle hardening, egg chorion tanning, wound healing, and immunity (Cerenius et al., 2008; Christensen et al., 2005; Nappi and Christensen, 2005). In the realm of immunity, melanization is an immune effector mechanism involved in the killing of bacteria, fungi, protozoan parasites, nematode worms, and the eggs of parasitoid wasps. When this process also involves the aggregation of hemocytes, it is known as nodulation or encapsulation (see sections 5.3 and 5.4). Melanization involves a series of reactions that includes the conversion of tyrosine to melanin precursors and the crosslinking of proteins to form a layer of melanin that surrounds and sequesters an invading pathogen. Melanization is phenotypically manifested as a darkened proteinaceous capsule that surrounds the invading pathogen, and the death of the pathogen presumably occurs via either 
oxidative damage or via starvation, as the foreign agent becomes isolated from the nutrient-rich hemolymph (Cerenius et al., 2008; Christensen et al., 2005; Nappi and Christensen, 2005). Melanization also assists in the clearing of dead or dying pathogens (Osta et al., 2004; Volz et al., 2006).

The process of melanization involves the coordinated interaction of pattern recognition receptors, serine proteases, serine protease inhibitors, and the enzymes that drive the production of melanin (Figure 5). This process begins when PRRs, such as $\beta-1,3$ glucan recognition proteins, C-type lectins and Gram-negative binding proteins, recognize PAMPs (Matskevich et al., 2010; Wang et al., 2014b; Wang et al., 2005). This initiates a serine protease cascade that culminates in the activation of pro-phenoloxidase activating enzymes that cleave the zymogen pro-phenoloxidase to its active form: phenoloxidase (An et al., 2011; An et al., 2009). Phenoloxidase initiates the production of melanin by hydroxylating tyrosine to form dopa, dopa is then oxidized by phenoloxidase to form dopaquinone, and this is converted to dopachrome (Christensen et al., 2005; Nappi and Christensen, 2005; Zhao et al., 1995). Dopachrome conversion enzyme converts dopachrome to 5,6-dihydroxyindole, phenoloxidase oxidizes it into indole-5,6-quinone, which is cross-linked with hemolymph proteins to form melanotic capsules. In a complementary pathway, dopa decarboxylase hydroxylates dopa to form dopamine, which is converted to melanin by phenoloxidase and other enzymes. The ratelimiting substrate in the melanization pathway is tyrosine. When additional tyrosine is needed to melanize large or numerous pathogens, endogenous production of tyrosine is accomplished by the hydroxylation of phenylalanine by phenylalanine hydroxylase.

Many of the enzymes and PRRs that drive the melanization response are produced by hemocytes, with oenocytoids (crystal cells) being the major producers of pro-phenoloxidase (Ashida et al., 1988; Hillyer et al., 2003a). Small pathogens that become melanized, such as bacteria, are often phagocytosed, and larger pathogens are often encapsulated by layers of hemocytes (Hillyer et al., 2003a, b; Pech and Strand, 1995, 1996). Because the enzymatic 
process that leads to melanization produces reactive oxygen species, these reactions are tightly regulated. Serine protease inhibitors, also known as Serpins, and other factors such as some C-type lectins, inhibit the activation of the phenoloxidase cascade (An et al., 2011; Osta et al., 2004). Finally, some of the proteins involved in melanization are members of protein families. For example, most insect genomes encode multiple phenoloxidases that have partially overlapping functions. For example, D. melanogaster PPO1 and PPO2 are involved in the antibacterial response whereas PPO2 and PPO3 are involved in the encapsulation response (Dudzic et al., 2015). Likewise, Armigeres subalbatus Pro-PO I is involved in the melanization of filarial worms, Pro-PO III is involved in cuticle formation, and Pro-PO V is involved in both parasite melanization and egg chorion tanning (Shiao et al., 2001; Tsao et al., 2015; Tsao et al., 2009).

\subsection{Cellular encapsulation}

Encapsulation is a cellular immune response used against pathogens that are too large to be phagocytosed. This response is commonly employed by dipteran and lepidopteran larvae in response to infection with the eggs of parasitoid wasps. In Lepidoptera, encapsulation is initiated when granulocytes attach to form a layer of cells that surrounds a pathogen, and this cell adhesion occurs in a manner that is dependent on the binding of integrins to specific sites defined by an Arg-Gly-Asp (RGD) sequence (Pech and Strand, 1995, 1996). The layer of granulocytes is then surrounded by several layers of plasmatocytes, and this is followed by the binding of additional granulocytes. A similar process occurs in Drosophila, except that the cells involved are plasmatocytes and lamellocytes (Russo et al., 1996). Depending on the pathogen and the insect, the capsule may become melanized.

\subsection{Nodulation}


Nodulation involves the coordinated adherence of hemocytes in a manner that surrounds large aggregates of bacteria, and this is usually followed by melanization (Ratcliffe and Gagen, 1977; Satyavathi et al., 2014). In this immune process, granulocytes adhere to each other and form layers that surround dense bacterial aggregates. The granulocytes release their contents, which encases the bacteria in a flocculent material. Plasmatocytes then aggregate around the surface of the nodule, and in most cases the entire structure becomes melanized. The molecular mechanisms behind this immune process remain poorly understood, but nodulation relies on eicosanoid-based signaling and the extracellular matrix-like protein, Noduler (Carton et al., 2002; Gandhe et al., 2007).

\subsection{Lysis}

Pathogen killing via lysis refers to death due to the immune-based disruption of the cellular membrane. From a practical perspective, entomologists often attribute pathogen death to lysis when an immune-based reduction in infection intensity is detected, but this reduction is not accompanied by an easily observable immune phenotype. That is, observing lysis is difficult whereas phagocytosis is observed because pathogens are seen inside of hemocytes, and melanization, cellular encapsulation, and nodulation are easily observed because large cellular aggregates, dense and dark melanin deposits, or both are formed.

Some of the earliest studied insect factors that induce pathogen death via lysis are the antimicrobial peptides, also known as AMPs. AMPs are secreted proteins that are usually between 2 and $20 \mathrm{kDa}$ in mass. These peptides and proteins were initially identified for their antimicrobial activity in vitro (Hoffmann and Hoffmann, 1990; Steiner et al., 1981; Vizioli et al., 2001). Based on their structural and sequence characteristics, most AMPs can be grouped into four categories, with many insect species producing multiple members of each (He et al., 2015; Imler, 2014; Yi et al., 2014). The Defensin and Defensin-like peptides include Defensin, Drosomycin, Holitricin, Sapecin and others. These peptides are rich in cysteines and contain 
cysteine disulfide bonds. Members of this type of AMP, which have been identified in Diptera, Hymenoptera, Hemiptera, Coleoptera and Lepidoptera, have activity against Gram(+) bacteria, but others also combat Gram(-) bacteria and fungi. The Cecropin and Cecropin-like peptides, including the Moricins, are $\alpha$-helical peptides that have been identified in Diptera, Coleoptera, and Lepidoptera. These peptides have activity against Gram(+) and Gram(-) bacteria, as well as fungi. The Attacins and Gloverins are glycine-rich peptides. Attacins, which have been identified in Diptera and Lepidoptera, are mainly active against Gram(-) bacteria, whereas the Gloverins, which have been identified only in Lepidoptera, have activity against Gram(+) bacteria, Gram(-) bacteria, or fungi. The Lebocins (Lebocin, Drosocin, Metchnikowin, and others) are proline-rich peptides that have been identified in Hemiptera, Hymenoptera, Lepidoptera, and Diptera, and are active against Gram(+) bacteria, Gram(-) bacteria, and some fungi. Other AMPs cannot be grouped in any of the above categories, yet are important components of the insect immune response. For example, Gambicin is produced by mosquitoes and possesses activity against Gram(+) bacteria, Gram(-) bacteria, fungi, and Plasmodium parasites (Vizioli et al., 2001). The production of antimicrobial peptides is governed by immune signaling pathways. In $D$. melanogaster, for example, activation of the Toll pathway induces the transcription of Drosomycin whereas activation of the Imd pathway induces the transcription of Diptericin (Lemaitre and Hoffmann, 2007).

Lysozymes are another family of proteins with lytic activity. Lysozymes hydrolyze the $\beta$ 1,4-glycosidic linkage between $\mathrm{N}$-acetylmuramic acid and $\mathrm{N}$-acetylglucosamine of the peptidoglycan present in the cell wall of bacteria. Most insect genomes encode multiple lysozymes; the genomes of Drosophila melanogaster, Anopheles gambiae, Manduca sexta, Tribolium castaneum, Apis mellifera, Acyrthosiphon pisum, Bombus terrestris, and Megachile rotundata encode 14, 8, 6, 4, 3, 3, 1 and 1 lysozymes, respectively (Barribeau et al., 2015; Evans et al., 2006; Gerardo et al., 2010; He et al., 2015; Waterhouse et al., 2007; Zou et al., 2007). Unlike AMPs, which are produced in response to an immune insult, lysozymes are 
usually present in low, constitutive levels and are transcriptionally upregulated following infection. Although lysozymes are classically active in the lytic antibacterial response (Elmogy et al., 2015; Kwon et al., 2014b), some also have anti-Plasmodium and anti-fungal activity (Kajla et al., 2011; Sowa-Jasilek et al., 2014), and can activate the phenoloxidase-based melanization pathway (Li and Paskewitz, 2006; Rao et al., 2010). In addition to being involved in immunity, some insect lysozymes are expressed in the gut and function in digestion (Ito et al., 1995; UrsicBedoya et al., 2008).

The function of reactive oxygen species in immune responses is arguably best known for the oxidative burst that leads to the destruction of organisms that have been internalized by phagocytes (Slauch, 2011). In addition to their function in this cellular response, reactive oxygen species and reactive nitrogen species effect lytic activity in the extracellular environment. For example, dual oxidase, which generates hydrogen peroxidase, regulates the antibacterial response in the intestinal space of fruit flies (Ha et al., 2005), and nitric oxide synthase, which produces nitric oxide via the oxidation of L-Arginine to L-Citrulline (Hughes, 2008), drives anti-Plasmodium activity in the gut of mosquitoes (Gupta et al., 2009; Luckhart et al., 1998). Reactive species are also involved in the antimicrobial response in the hemocoel. For example, nitric oxide, which functions as both a messenger molecule and an immune effector, is produced by hemocytes and is an important component of the antibacterial response (Hillyer and Estevez-Lao, 2010; Nappi et al., 2000).

\subsection{RNA interference}

RNA interference, or RNAi, is an RNA-based mechanism for gene silencing. From an experimental perspective, scientists have taken advantage of the insect's own RNAi machinery to study the function of insect genes, and it has been proposed that RNAi could be used for the management of insect pests (Scott et al., 2013; Yu et al., 2013). Nevertheless, one of the 
natural functions of RNAi is to protect the organism from viral infection (Blair and Olson, 2014; Bronkhorst and van Rij, 2014; Karlikow et al., 2014; Sim et al., 2014).

The primary RNAi pathway that participates in the antiviral response is the small interfering RNA pathway (siRNA, or exo-siRNA for exogenous siRNA), whereby viral double stranded RNA (dsRNA) is cleaved by a ribonuclease, called Dicer-2 (Dcr2), that forms a complex with its cofactor R2D2 (Figure 6). This cleavage produces viral-derived small interfering RNAs (siRNAs) that are usually 21 nucleotides in length, and these siRNAs are loaded into pre-RNA induced silencing complexes (RISC) that include Argonaute-2 (Ago2). The siRNA in a RISC complex is unwound, one strand is discarded, and the other binds complementary viral RNA, which triggers its destruction by Ago2. The binding of viral RNA by Dcr2 also activates the transcription of Vago, which is a cysteine-rich polypeptide that negatively controls virus replication (Deddouche et al., 2008). In mosquitoes, the transcriptional activation of Vago is mediated by an NF-kB transcription factor associated with the Imd pathway (Rel2), and in turn, Vago activates the Jak-Stat pathway (Paradkar et al., 2012).

In addition to the siRNA pathway, the PIWI-associated RNA pathway (piRNA) also functions in the RNAi-mediated antiviral defense of mosquitoes (Blair and Olson, 2014; Bronkhorst and van Rij, 2014). piRNAs are 25-30 nucleotides in length and associate with the PIWI clade of Argonaute proteins. The piRNA pathway operates in a manner that is independent of Dicer.

\subsection{Autophagy}

Autophagy is an evolutionary conserved process utilized for the degradation of intracellular materials. In both vertebrate and invertebrate animals, autophagy is employed for the elimination of intracellular pathogens such as bacteria and viruses (Lamiable and Imler, 2014; Moy and Cherry, 2013; Shibutani et al., 2015; Yano and Kurata, 2011). At the molecular level, autophagy is initiated via the interaction of Toll-7 in the plasma membrane with viral 
factors, which triggers the downregulation of the phosphatidylinositol 3-kinase (PI3K)-Akt pathway, thus inactivating the negative regulator of autophagy, target of rapamycin (TOR). Inactivation of TOR activates a complex containing the protein kinase Atg1 and the phosphoprotein Atg13 and this leads to the nucleation of the autophagosomal membrane via a complex that contains Atg14, Vps15 and Vps34. Following nucleation, the autophagosomal membrane elongates in a process that is dependent on both an Atg5/Atg12 complex and the conjugation of phosphatidylethanolamine to Atg8. The elongated membrane then closes to form an intracellular autophagosome, which then fuses with lysozomes, triggering the degradation of the engulfed contents. In Drosophila, autophagy is employed in the immune response against vesicular stomatitis virus and Rift Valley fever virus (Moy et al., 2014; Shelly et al., 2009). Autophagy, however, also enhances infection with Sindbis virus (Patel and Hardy, 2012).

\subsection{Apoptosis}

Apoptosis is a form of programmed cell death. This process is critical during the development of both vertebrate and invertebrate animals (Suzanne and Steller, 2013). At the molecular level, the caspase, Dronc, and the adaptor protein, Ark, form a complex. Dronc activates effector caspases such as Drice and Dcp1, and these caspases cleave proteins in a manner that eventually leads to programmed cell death (Cao et al., 2015). In Lepidoptera, apoptosis is involved in the response against baculoviruses (Clem, 2007). In mosquitoes, this process appears to be involved in the response against West Nile Virus and Sindbis virus (Vaidyanathan and Scott, 2006; Wang et al., 2012), and in the fruit fly, apoptosis protects against Drosophila C virus in a manner that is dependent on the phagocytosis of virus-infected apoptotic cells (Nainu et al., 2015). Some immune factors (e.g., Imd and Inhibitor of apoptosis protein 2, or IAP2) influence both the Imd and apoptosis pathways (Georgel et al., 2001; Gesellchen et al., 2005). 


\section{Immune responses and hemolymph circulation}

The hemocoel is a dynamic environment where hemolymph is continuously propelled to all the regions of the body by a series of autonomous pumps. The primary pump is the dorsal vessel, which is a muscular tube that extends the length of the body along the dorsal midline of the insect and is divided into a heart in the abdomen and an aorta in the thorax (Ejaz and Lange, 2008; Glenn et al., 2010; League et al., 2015; Wasserthal, 2007). In most adult insects, the heart periodically alternates between propelling hemolymph toward the head (anterograde direction) and propelling hemolymph toward the posterior of the abdomen (retrograde direction) (Gerould, 1933; Glenn et al., 2010; League et al., 2015; Wasserthal, 2007). During anterograde contractions, hemolymph enters the heart via valves, called ostia, that are located in each abdominal segment, and exits the vessel through an excurrent opening located near the head (Glenn et al., 2010; League et al., 2015). During retrograde contractions, hemolymph enters the heart through a pair of ostia located at the thoraco-abdominal junction and exits through excurrent openings located at the terminal abdominal segment. Once in the hemocoel, hemolymph flows toward the ostia and re-enters the heart (Andereck et al., 2010; Glenn et al., 2010; Lee and Socha, 2009). Insects also possess a series of accessory pulsatile organs, or auxiliary hearts, that propel hemolymph into the appendages (e.g., antennae, wings, and some reproductive structures) and other areas of the body that would otherwise experience little flow (Andereck et al., 2010; Boppana and Hillyer, 2014; Hustert et al., 2014; Lehmacher et al., 2009). The above description details what generally occurs in adult stage Diptera, but there are variations to this plan. For example, the heart of immature insects and some adult insects only contracts anterograde, some insects contain segmental vessels that extend laterally from the heart, and the location, number and function of the ostia varies between species and life stages (Ejaz and Lange, 2008; Gerould, 1933; Hertel and Pass, 2002; League et al., 2015). 
Pathogens, circulating hemocytes and humoral immune factors present in the hemocoel move throughout the body with the flow of hemolymph, and sessile hemocytes, fat body and all internal organs are exposed to a steady stream of this fluid (Babcock et al., 2008; Hillyer et al., 2007; King and Hillyer, 2012; Paulson and Grimstad, 1989). Immune processes such as phagocytosis, melanization and lysis occur both in circulation and at sessile locations (Borges et al., 2008; Hillyer et al., 2003a, b; King and Hillyer, 2013; Kwon et al., 2014a), and in response to injury, circulating hemocytes adhere to wounds and initiate a healing response that usually involves melanization (Babcock et al., 2008; Krautz et al., 2014; Lai et al., 2001; Rowley and Ratcliffe, 1978). The distribution of circulating and sessile hemocytes can dynamically change, including the attachment of circulating hemocytes to sessile tissues and the release of sessile hemocytes into circulation (Babcock et al., 2008; King and Hillyer, 2012, 2013; Markus et al., 2009; Sigle and Hillyer, 2016).

Many insect immune responses take place as hemocytes passively flow with the hemolymph. Others, however, actively take advantage of circulatory currents (Figure 7). This co-adaptation of the circulatory and immune systems has been most comprehensively demonstrated in mosquitoes, where these flies possess a resident population of sessile hemocytes - called periostial hemocytes - that are positioned in the extracardiac regions that are immediately adjacent to the ostia (King and Hillyer, 2012). Upon infection, periostial hemocytes rapidly begin to phagocytose pathogens at these locations of high hemolymph flow, and as this occurs, additional hemocytes arrive at the heart, adhere to the periostial hemocytes and the cardiac-associated musculature, and amplify this phagocytic response. The periostial regions of the heart are the sessile areas of the body that contain the highest density of hemocytes, and once periostial hemocyte aggregation is initiated, elevated numbers of hemocytes remain at these locations for the lifetime of the insect (King and Hillyer, 2012, 2013). Along the length of the heart, hemocyte aggregation is asymmetric, with the majority of hemocytes congregating at the periostial regions that receive the most hemolymph flow, thus 
placing immune cells at the locations of the body where they are most likely to encounter, and kill, circulating pathogens (Sigle and Hillyer, 2016). The aggregation of pathogens on the surface of the heart has been observed in Diptera and Lepidoptera (Bao et al., 2011; ElrodErickson et al., 2000; Hillyer et al., 2007; King and Hillyer, 2012, 2013; Pereira et al., 2015; Sigle and Hillyer, 2016), and hemocytes in or on the heart have been detected in Diptera, Lepidoptera, and Orthoptera (da Silva et al., 2012; Ghosh et al., 2015; King and Hillyer, 2012, 2013; Pereira et al., 2015; Sigle and Hillyer, 2016). Interactions between the immune and circulatory systems extend past the insects and into other members of Pancrustacea (Hillyer, 2015).

\section{Hematopoiesis}

Hemocytes are the primary immune cells of insects, and the production of these cells occurs during all life stages. Hematopoiesis, and more specifically hematopoiesis during the embryonic and immature stages, has been most comprehensively described for the model insect, $D$. melanogaster. In the embryo of the fruit fly, hemocytes are produced when cells from the procephalic mesoderm differentiate into plasmatocytes and crystal cells, and this is mediated by the GATA transcription factor, Serpent (Holz et al., 2003; Honti et al., 2014; Wood and Jacinto, 2007). The differentiation of plasmatocytes, which are the vast majority of the hemocytes, occurs as the mesodermal cells disperse throughout the embryo in a developmentally programmed manner, and requires the activity of Glial cells missing (Gcm) and Glial cells missing 2 (Gcm2). The differentiation of crystal cells involves non-dispersing mesodermal cells that congregate around the proventriculus, and requires the transcription factor Lozenge and Serrate/Notch signaling. In the larva, additional hemocytes are produced within a hematopoietic organ called the lymph gland, which is derived from the cardiogenic mesoderm (Holz et al., 2003; Honti et al., 2014; Jung et al., 2005). The lymph gland is anatomically divided into primary and secondary lobes that are positioned along the anterior 
portion of the dorsal vessel. The primary lobes are further divided into a posterior signaling center, an inner medullary zone and an outer cortical zone, with the posterior signaling center and the inner medullary zone containing prohemocytes at different stages of differentiation and the cortical zone containing plasmatocytes and crystal cells (Jung et al., 2005). Hemocyte differentiation in the primary lobes of the lymph gland involves the $\mathrm{InR} / \mathrm{TOR}$, Jak/Stat, and other pathways (Honti et al., 2014; Wood and Jacinto, 2007), and mature hemocytes are released from the lymph gland during a larval infection and shortly prior to pupation, at which point the lymph gland begins a degeneration process that is completed around the time of eclosion (Lanot et al., 2001). The secondary lobes contain prohemocytes that survive into adulthood, at which point they give rise to hematopoietic hubs that flank the anterior portion of the heart (Ghosh et al., 2015). In the larval stages, patches of sessile hemocytes that are attached to the integument, as well as circulating hemocytes, produce additional hemocytes by undergoing mitosis and cellular differentiation (Lanot et al., 2001; Leitao and Sucena, 2015; Markus et al., 2009).

In non-drosophilid Diptera, the process of hematopoiesis has also been examined in mosquitoes. Unlike for $D$. melanogaster, where hematopoiesis has primarily been scrutinized during the larval stages, hemocyte proliferation in mosquitoes has been exclusively assessed in the adult life stage, and this is likely because it is this stage that transmits disease-causing pathogens to humans and animals. In adults from both major families of mosquitoes, the Culicinae and the Anophelinae, imbibing blood induces the replication of hemocytes, and this replication is controlled by insulin signaling and Ras-MAPK signaling (Bryant and Michel, 2014; Castillo et al., 2011). Blood feeding-induced hemocyte proliferation is transient, as by $36 \mathrm{~h}$ post feeding the mitotic rate of hemocytes returns to near baseline levels (Bryant and Michel, 2016). During the course of some infections, the number of hemocytes in the hemocoel also increases, and this is at least in part due to the mitosis of circulating hemocytes (Christensen et al., 1989; Coggins et al., 2012; King and Hillyer, 2013). 
In immature Lepidoptera, hemocyte proliferation and differentiation also relies on embryonically-derived hemocytes as well as hemocytes produced in compact, hematopoietic organs that are positioned in the mesothorax and the metathorax, near the imaginal wing discs (Akai and Sato, 1971; Gardiner and Strand, 2000; Monpeyssin and Beaulaton, 1978; Nardi, 2004; Nardi et al., 2003). Much like in Drosophila, hemocyte production occurs via both the mitosis of embryonic hemocytes, and via the differentiation of cells within the hematopoietic organs (Gardiner and Strand, 2000; Mangalika et al., 2010; Nakahara et al., 2003; Tan et al., 2013). During the late larval stages, these hematopoietic organs release mature hemocytes into circulation and then degenerate around the time of metamorphosis. The molecular basis of hemocyte replication in Lepidoptera is not well understood, but it involves insulin signaling and Noduler-based activation of p38 mitogen-activated protein kinase (Nakahara et al., 2006; Satyavathi et al., 2015).

Hemocyte replication in other insect orders has not been studied in great detail. However, hematopoietic organs have been described in Orthoptera, and for one member of this group (Locusta migratoria) it was shown that an immune challenge during the adult stage induces an increase in hemocyte numbers, with this increase being primarily due to the mitosis of circulating hemocytes (Duressa et al., 2015). The proliferation of hemocytes has also been reported in Blattodea and Hemiptera, although the spatial and molecular mechanics of these mitotic events have not been elucidated (Feir and O'Connor, 1965; Tauber, 1940). Finally, although hemocytes are divided into functionally distinct populations, experiments in both Diptera and Lepidoptera show, or suggest, that a mature hemocyte can give rise to a different functional morphotype (e.g., plasmatocytes giving rise to crystal cells), demonstrating the plasticity of the hemocyte lineages (Honti et al., 2010; Leitao and Sucena, 2015; Nakahara et al., 2003).

\section{Immune priming}


The adaptive immune response of vertebrate animals relies on somatic hypermutation and $\mathrm{V}(\mathrm{D}) \mathrm{J}$ recombination to create highly diverse repertoires of antibodies and $\mathrm{T}$ cell receptors that specifically recognize invaders (Murphy, 2011). This process also allows for immune memory, where exposure to a given pathogen induces the development of cells that are specifically tuned to that pathogen. The presence of these memory cells allows the organism to mount a more rapid and powerful immune response when it is re-exposed to the same pathogen or a highly related one. This type of adaptive immune response, as classically defined for the vertebrate immune system, does not occur in insects.

Insects, however, employ other tactics to protect themselves from re-infection. Studies on a diverse group of insects have shown that a sub-lethal infection can provide partial or full protection from a subsequent infection (Masri and Cremer, 2014). Protection is sometimes specific to the pathogen already encountered (Pham et al., 2007; Roth et al., 2009; Sadd and Schmid-Hempel, 2006). Most often, however, protection is conferred against other pathogens as well, or protection from re-infection with the same pathogen is clearly established but the specificity of the protection remains unknown (Contreras-Garduno et al., 2015; Moret and SivaJothy, 2003; Rodrigues et al., 2010). The length of the protection may last the lifetime of the insect (although most of these studies have been performed in short-lived insects), or may last only for only a few days (Moret and Siva-Jothy, 2003; Pham et al., 2007). In addition, protection from infection may be conferred to the offspring (Moret and Schmid-Hempel, 2001; TrauerKizilelma and Hilker, 2015), may be passed along to the nestmates (Traniello et al., 2002; Ugelvig and Cremer, 2007), and may persist across molts (Bargielowski and Koella, 2009; Thomas and Rudolf, 2010).

The mechanisms underlying immune priming in insects are poorly understood. It has been hypothesized that immune priming occurs because the insect is inherently able to activate immune responses more rapidly during a second exposure, or because pathogens or pathogen components are retained within the insect, which maintains the animal in a heightened state of 
immune alertness (Masri and Cremer, 2014). Although immune priming has been demonstrated in multiple insect orders, it is not a universal feature of the insect immune system, nor is it universal for all infection types (Gonzalez-Tokman et al., 2010; Reber and Chapuisat, 2012).

\section{Environmental factors and immune responses}

The strength and composition of an immune response is impacted by factors that are independent of the nature of the infection. One of these factors is temperature. Insects are poikilotherms, and thus, their temperature fluctuates with the temperature of the environment. The environmental temperature during an infection, or even the temperature experienced earlier in life, can affect the anti-pathogen response. Temperature affects the immune response of mosquitoes, but these changes are complex and do not simply scale with temperature (Murdock et al., 2012). For example, temperatures that favor the expression of nitric oxide synthase are less favorable for phenoloxidase-based melanization, and vice versa. These complexities have also been observed in crickets, where elevated temperatures are advantageous when fighting some types of pathogens but not others (Adamo and Lovett, 2011). Within a species, the strength of the immune response varies with both temperature and genotype. For example, $D$. melanogaster that were collected in tropical regions of the world were less capable of mounting immune responses when placed at a low temperature when compared to similarly treated flies that had been originally collected in temperate locations (Lazzaro et al., 2008). Finally, temperature-associated stress can affect the strength of immune responses mounted later in life, as reported for the deer ked, Lipoptena cervi (Kaunisto et al., 2015).

In addition to temperature, other external factors influence immune responses. The availability of resources and the composition of those resources affects the strength of insect immune responses (Boots, 2011; Cotter et al., 2011). Likewise, ambient humidity and the circadian clock also impact the strength and composition of an immune response (Lee and 
Edery, 2008; Mostafa et al., 2005). For example, the time of day when a fruit fly is infected influences the probability of survival, and this is at least in part due to the modulation of phagocytosis by the circadian clock protein, Timeless (Lee and Edery, 2008; Stone et al., 2012).

\section{Insect age and immune responses}

The age of an insect impacts the response to infection. In adult insects, the general observation is one of immunosenescence, where the strength of the immune response decreases with age. Such observations have been made in Diptera, Hymenoptera, Lepidoptera, Coleoptera, and Odonata. Often, senescence refers to a decrease in the potency of a response that involves encapsulation, nodulation or melanization (Daukste et al., 2012; Park et al., 2011; Prasai and Karlsson, 2012; Robb and Forbes, 2006), or refers to a decrease in the number of hemocytes or their phagocytic activity (Hillyer et al., 2005; Horn et al., 2014; Mackenzie et al., 2011; Park et al., 2011; Pigeault et al., 2015; Schmid et al., 2008). This senescence often results in increased infection intensities in older insects, which may be accompanied by either increased (Roberts and Hughes, 2014) or decreased (Hillyer et al., 2005) survival. Seemingly conflicting with the concept of immunosenescence, reports on insect vectors have demonstrated that older flies are less capable of becoming infected with - and transmitting - malaria parasites, filarial nematodes, or the parasites that cause human African trypanosomiasis (Aksoy et al., 2014; Ariani et al., 2015; Pigeault et al., 2015), indicating that the relationship between immunity, tolerance, and aging is complex.

\section{Social immunity}

The anti-pathogen response of insects has been most intensely studied at the level of the individual, with most of this work focusing on internal factors that protect an organism from an infectious agent. In addition to these individual responses, several groups of insects mount collective, anti-pathogen defenses, and these defenses are referred to as social immunity. 
Investigations into social immunity initially focused on eusocial insects, and defined this process as the collective action or altruistic behaviors of insects that result in the avoidance, control or elimination of parasitic infections (Cremer et al., 2007). Subsequent studies broadened this definition to include non-eusocial insects, and defined social immunity as (1) immune responses that have been selected to increase the fitness of a challenged individual and one or more recipient (Cotter and Kilner, 2010), or (2) collective and personal mechanisms that are maintained at least in part by the anti-pathogen defense they provide to other members of the group (Meunier, 2015). Examples of social immunity include, but are not limited to, avoiding contaminated habitats (Rozen et al., 2008), collecting antimicrobial substances (SimoneFinstrom and Spivak, 2010), depositing materials with antimicrobial properties on the nest or brood (Baracchi et al., 2012; Reavey et al., 2014), removing infected or dead individuals (Diez et al., 2012), allogrooming (Walker and Hughes, 2009), social fever (Starks et al., 2000), transgenerational immune priming (Moret and Schmid-Hempel, 2001; Rosengaus et al., 2013; Trauer-Kizilelma and Hilker, 2015), and immune priming of nestmates (Traniello et al., 2002; Ugelvig and Cremer, 2007).

\section{Concluding remarks}

Over the past few decades it has become exceedingly clear that the insect immune system is composed of a complex network of components that synergistically form barriers that prevent or fight infection. Multiple tissues, led by the hemocytes, work in concert to combat invading pathogens, and the molecular underpinnings of immune processes are becoming well understood. However, many aspects of the insect immune response remain unknown or underexplored, and the remainder of this section highlights a few of these areas.

Insects are the most speciose group of animals, with thirty orders (give or take a few, depending on the analysis) that contain approximately one million taxonomically described species (Gullan and Cranston, 2014; Misof et al., 2014; Trautwein et al., 2012). Yet, our 
understanding of insect immunity comes primarily from studies conducted in Diptera and Lepidoptera, which are closely related holometabolous insect orders. The immune systems of hemimetabolous insects, with the exception of some members of Hemiptera, have gone largely ignored. Similarly, with some notable exceptions (Park et al., 2010; Zou et al., 2007), comparatively little is known about the immune system of the most speciose group of insects, the Coleoptera (beetles), which contains over one third of the described insect species. Even within the Diptera, which is the taxonomic group that has received the most attention, taxon coverage has been sparse. This group contains over 150,000 species that are classified into 130 families (Yeates and Wiegmann, 1999), yet most of what we know about the immune system of dipterans has focused on two families: Drosophilidae (fruit flies) and Culicidae (mosquitoes). Even within the Culicidae, which contains approximately 3,500 described species (Reidenbach et al., 2009), most studies gave concentrated on three species: Anopheles gambiae, Aedes aegypti, and to a lesser extent, Culex quinquefasciatus. Thus, the field of insect immunity is fairly mature in some taxa but largely underexplored in others.

Within a taxonomic group, studies on insect immunity have often shown a developmental bias. In D. melanogaster, studies pertaining to hematopoiesis have almost exclusively focused on the larval stages (Honti et al., 2014). Studies in Lepidoptera have also mainly focused on the larvae (Jiang et al., 2010), whereas studies on mosquitoes have focused almost exclusively in the adult life stage (Clayton et al., 2014; Hillyer, 2010). The ecology of an insect species often varies dramatically between life stages (e.g., from aquatic to aerial, or from subterranean to above ground), and these changes, together with the reproductive status of the insect, are expected to impact pathogen-associated immune responses.

Many questions also remain pertaining to how insects with greatly different life histories fight infection. For example, immunity-based studies conducted on Diptera and Lepidoptera have focused on species with relatively short lifespans. Fruit flies, mosquitoes, the silkworm, and the tobacco hornworm, to name a few, all have life cycles that can be completed in a few 
weeks, although diapause can extend this timeline. In contrast, some insects live longer than a year, and in the extreme case of periodical cicadas, these insects live thirteen or seventeen years prior to reaching sexual maturity (Sota et al., 2013). Whether there are significant differences in the manner in which long-lived insects combat infection, relative to their shorterlived counterparts, remains a mystery.

Hemocyte classification and biology has often been a controversial topic. Hemocytes have been examined by light microscopy for many insect species, and most initial studies have relied exclusively on morphology to create hemocyte classification nomenclatures. Subsequent studies at the functional, cytochemical or molecular levels have validated those morphological classifications or revised them, with revisions usually resulting in a reduction in the number of accepted cell types (Hillyer and Strand, 2014; Strand, 2008). Even when the nomenclature systems are properly validated, a lack of communication between investigators working on different species has led to cells that are functionally and morphologically similar being named differently (Hillyer and Christensen, 2002; Strand, 2008). Within a species, different nomenclatures continue to exist, as has been reported, for example, for the pea aphid (Laughton et al., 2011; Schmitz et al., 2012). In attempts to circumvent this problem, some investigators have proposed that the names of hemocyte sub-types be normalized (Ribeiro and Brehelin, 2006), but such a normalized terminology has not been adopted, perhaps because real differences indeed exist due to the 400 million year evolutionary history of the class Insecta. The field of hemocyte biology is ripe with questions, but initial studies on any insect should seek to balance structure and function, while being mindful of the nomenclatures used in related taxa.

Finally, our understanding of the molecular basis of immunity is advancing at a rapid pace. This has been facilitated by the continuous development and accessibility of next generation sequencing technologies, genomic approaches, and both RNAi- and transgenicbased methods to modify gene expression. A continued pursuit of the molecular basis of 
immune effectors, pathways, and their cross-talk, will continue to inform not only on how insects combat infection, but will also inform on how the immune system of animals has evolved.

\section{Acknowledgments}

This work was supported by NSF grant IOS-1456844 and NIH grant R21Al119596 to J.F.H.

\section{References}

Adamo, S.A., Lovett, M.M., 2011. Some like it hot: the effects of climate change on reproduction, immune function and disease resistance in the cricket Gryllus texensis. J Exp Biol 214, 1997-2004.

Aggarwal, K., Silverman, N., 2008. Positive and negative regulation of the Drosophila immune response. BMB Rep 41, 267-277.

Akai, H., Sato, S., 1971. An ultrastructural study of the haemopoietic organs of the silkworm, Bombyx mori. J Insect Physiol 17, 1665-1676.

Aksoy, S., Weiss, B.L., Attardo, G.M., 2014. Trypanosome transmission dynamics in tsetse. Curr Opin Insect Sci 3, 43-49.

An, C., Budd, A., Kanost, M.R., Michel, K., 2011. Characterization of a regulatory unit that controls melanization and affects longevity of mosquitoes. Cell Mol Life Sci 68, 19291939.

An, C., Ishibashi, J., Ragan, E.J., Jiang, H., Kanost, M.R., 2009. Functions of Manduca sexta hemolymph proteinases HP6 and HP8 in two innate immune pathways. J Biol Chem 284, 19716-19726.

Andereck, J.W., King, J.G., Hillyer, J.F., 2010. Contraction of the ventral abdomen potentiates extracardiac retrograde hemolymph propulsion in the mosquito hemocoel. PLoS One 5, e12943.

Ariani, C.V., Juneja, P., Smith, S., Tinsley, M.C., Jiggins, F.M., 2015. Vector competence of Aedes aegypti mosquitoes for filarial nematodes is affected by age and nutrient limitation. Exp Gerontol 61, 47-53.

Ashida, M., Ochiai, M., Niki, T., 1988. Immunolocalization of prophenoloxidase among hemocytes of the silkworm, Bombyx mori. Tissue Cell 20, 599-610.

Babcock, D.T., Brock, A.R., Fish, G.S., Wang, Y., Perrin, L., Krasnow, M.A., Galko, M.J., 2008. Circulating blood cells function as a surveillance system for damaged tissue in Drosophila larvae. Proc Natl Acad Sci U S A 105, 10017-10022.

Bao, Y.Y., Xue, J., Wu, W.J., Wang, Y., Lv, Z.Y., Zhang, C.X., 2011. An immune-induced reeler protein is involved in the Bombyx mori melanization cascade. Insect Biochem Mol Biol 41, 696-706.

Baracchi, D., Mazza, G., Turillazzi, S., 2012. From individual to collective immunity: the role of the venom as antimicrobial agent in the Stenogastrinae wasp societies. J Insect Physiol 58, 188-193.

Bargielowski, I., Koella, J.C., 2009. A possible mechanism for the suppression of Plasmodium berghei development in the mosquito Anopheles gambiae by the microsporidian Vavraia culicis. PLoS One 4, e4676. 
Barribeau, S.M., Sadd, B.M., du Plessis, L., Brown, M.J., Buechel, S.D., Cappelle, K., Carolan, J.C., Christiaens, O., Colgan, T.J., Erler, S., Evans, J., Helbing, S., Karaus, E., Lattorff, H.M., Marxer, M., Meeus, I., Napflin, K., Niu, J., Schmid-Hempel, R., Smagghe, G., Waterhouse, R.M., Yu, N., Zdobnov, E.M., Schmid-Hempel, P., 2015. A depauperate immune repertoire precedes evolution of sociality in bees. Genome Biol 16, 83.

Blair, C.D., Olson, K.E., 2014. Mosquito immune responses to arbovirus infections. Curr Opin Insect Sci 3, 22-29.

Boots, M., 2011. The evolution of resistance to a parasite is determined by resources. Am Nat $178,214-220$.

Boppana, S., Hillyer, J.F., 2014. Hemolymph circulation in insect sensory appendages: functional mechanics of antennal accessory pulsatile organs (auxiliary hearts) in the mosquito Anopheles gambiae. J Exp Biol 217, 3006-3014.

Borges, A.R., Santos, P.N., Furtado, A.F., Figueiredo, R.C., 2008. Phagocytosis of latex beads and bacteria by hemocytes of the triatomine bug Rhodnius prolixus (Hemiptera: Reduvidae). Micron 39, 486-494.

Boutros, M., Agaisse, H., Perrimon, N., 2002. Sequential activation of signaling pathways during innate immune responses in Drosophila. Dev Cell 3, 711-722.

Brennan, C.A., Delaney, J.R., Schneider, D.S., Anderson, K.V., 2007. Psidin is required in Drosophila blood cells for both phagocytic degradation and immune activation of the fat body. Curr Biol 17, 67-72.

Bronkhorst, A.W., van Rij, R.P., 2014. The long and short of antiviral defense: small RNA-based immunity in insects. Curr Opin Virol 7, 19-28.

Bryant, W.B., Michel, K., 2014. Blood feeding induces hemocyte proliferation and activation in the African malaria mosquito, Anopheles gambiae Giles. J Exp Biol 217, 1238-1245.

Bryant, W.B., Michel, K., 2016. Anopheles gambiae hemocytes exhibit transient states of activation. Dev Comp Immunol DOI: 10.1016/j.dci.2015.10.020.

Buchon, N., Broderick, N.A., Poidevin, M., Pradervand, S., Lemaitre, B., 2009. Drosophila intestinal response to bacterial infection: activation of host defense and stem cell proliferation. Cell Host Microbe 5, 200-211.

Cao, X., He, Y., Hu, Y., Wang, Y., Chen, Y.R., Bryant, B., Clem, R.J., Schwartz, L.M., Blissard, G., Jiang, H., 2015. The immune signaling pathways of Manduca sexta. Insect Biochem Mol Biol 62, 64-74.

Carton, Y., Frey, F., Stanley, D.W., Vass, E., Nappi, A.J., 2002. Dexamethasone inhibition of the cellular immune response of Drosophila melanogaster against a parasitoid. J Parasitol 88, 405-407.

Castillo, J., Brown, M.R., Strand, M.R., 2011. Blood feeding and insulin-like peptide 3 stimulate proliferation of hemocytes in the mosquito Aedes aegypti. PLoS Pathog 7, e1002274.

Castillo, J.C., Robertson, A.E., Strand, M.R., 2006. Characterization of hemocytes from the mosquitoes Anopheles gambiae and Aedes aegypti. Insect Biochem Mol Biol 36, 891903.

Cerenius, L., Lee, B.L., Soderhall, K., 2008. The proPO-system: pros and cons for its role in invertebrate immunity. Trends Immunol 29, 263-271.

Chevignon, G., Cambier, S., Da Silva, C., Poulain, J., Drezen, J.M., Huguet, E., Moreau, S.J., 2015. Transcriptomic response of Manduca sexta immune tissues to parasitization by the bracovirus associated wasp Cotesia congregata. Insect Biochem Mol Biol 62, 86-99.

Choe, K.M., Werner, T., Stoven, S., Hultmark, D., Anderson, K.V., 2002. Requirement for a peptidoglycan recognition protein (PGRP) in Relish activation and antibacterial immune responses in Drosophila. Science 296, 359-362.

Christensen, B.M., Huff, B.M., Miranpuri, G.S., Harris, K.L., Christensen, L.A., 1989. Hemocyte population changes during the immune response of Aedes aegypti to inoculated microfilariae of Dirofilaria immitis. J Parasitol 75, 119-123. 
Christensen, B.M., Li, J., Chen, C.C., Nappi, A.J., 2005. Melanization immune responses in mosquito vectors. Trends Parasitol 21, 192-199.

Christensen, B.M., Sutherland, D.R., 1984. Brugia pahangi: exsheathment and midgut penetration in Aedes aegypti. Trans Am Microsc Soc 103, 423-433.

Cirimotich, C.M., Dong, Y., Clayton, A.M., Sandiford, S.L., Souza-Neto, J.A., Mulenga, M., Dimopoulos, G., 2011. Natural microbe-mediated refractoriness to Plasmodium infection in Anopheles gambiae. Science 332, 855-858.

Clayton, A.M., Dong, Y., Dimopoulos, G., 2014. The Anopheles innate immune system in the defense against malaria infection. J Innate Immun 6, 169-181.

Clem, R.J., 2007. Baculoviruses and apoptosis: a diversity of genes and responses. Curr Drug Targets 8, 1069-1074.

Coggins, S.A., Estevez-Lao, T.Y., Hillyer, J.F., 2012. Increased survivorship following bacterial infection by the mosquito Aedes aegypti as compared to Anopheles gambiae correlates with increased transcriptional induction of antimicrobial peptides. Dev Comp Immunol 37, 390-401.

Contreras-Garduno, J., Rodriguez, M.C., Hernandez-Martinez, S., Martinez-Barnetche, J., Alvarado-Delgado, A., Izquierdo, J., Herrera-Ortiz, A., Moreno-Garcia, M., VelazquezMeza, M.E., Valverde, V., Argotte-Ramos, R., Rodriguez, M.H., Lanz-Mendoza, H., 2015. Plasmodium berghei induced priming in Anopheles albimanus independently of bacterial co-infection. Dev Comp Immunol 52, 172-181.

Costa-Leonardo, A.M., Laranjo, L.T., Janei, V., Haifig, I., 2013. The fat body of termites: functions and stored materials. J Insect Physiol 59, 577-587.

Cotter, S.C., Kilner, R.M., 2010. Personal immunity versus social immunity. Behav Ecol 21, 663668.

Cotter, S.C., Simpson, S.J., Raubenheimer, D., Wilson, K., 2011. Macronutrient balance mediates trade-offs between immune function and life history traits. Funct Ecol 25, 186198.

Cremer, S., Armitage, S.A., Schmid-Hempel, P., 2007. Social immunity. Curr Biol 17, R693-702. da Silva, R., da Silva, S.R., Lange, A.B., 2012. The regulation of cardiac activity by nitric oxide (NO) in the Vietnamese stick insect, Baculum extradentatum. Cell Signal 24, 1344-1350.

Das, S., Dong, Y., Garver, L., Dimopoulos, G., 2009. Specificity of the innate immune system: a closer look at the mosquito pattern-recognition repertoire, in: Rolff, J., Reynolds, S.E. (Eds.), Insect infection and immunity: evolution, ecology, and mechanics. Oxford University Press, Oxford UK, pp. 69-85.

Daukste, J., Kivleniece, I., Krama, T., Rantala, M.J., Krams, I., 2012. Senescence in immune priming and attractiveness in a beetle. J Evol Biol 25, 1298-1304.

Dean, P., Potter, U., Richards, E.H., Edwards, J.P., Charnley, A.K., Reynolds, S.E., 2004. Hyperphagocytic haemocytes in Manduca sexta. J Insect Physiol 50, 1027-1036.

Deddouche, S., Matt, N., Budd, A., Mueller, S., Kemp, C., Galiana-Arnoux, D., Dostert, C., Antoniewski, C., Hoffmann, J.A., Imler, J.L., 2008. The DExD/H-box helicase Dicer-2 mediates the induction of antiviral activity in Drosophila. Nat Immunol 9, 1425-1432.

Diez, L., Deneubourg, J.L., Detrain, C., 2012. Social prophylaxis through distant corpse removal in ants. Naturwissenschaften 99, 833-842.

Dong, Y., Taylor, H.E., Dimopoulos, G., 2006. AgDscam, a hypervariable immunoglobulin domain-containing receptor of the Anopheles gambiae innate immune system. PLoS Biol 4, e229.

Dudzic, J.P., Kondo, S., Ueda, R., Bergman, C.M., Lemaitre, B., 2015. Drosophila innate immunity: regional and functional specialization of prophenoloxidases. BMC Biol 13, 81.

Duressa, T.F., Vanlaer, R., Huybrechts, R., 2015. Locust cellular defense against infections: sites of pathogen clearance and hemocyte proliferation. Dev Comp Immunol 48, 244253. 
Ejaz, A., Lange, A.B., 2008. Peptidergic control of the heart of the stick insect, Baculum extradentatum. Peptides 29, 214-225.

Elmogy, M., Bassal, T.T., Yousef, H.A., Dorrah, M.A., Mohamed, A.A., Duvic, B., 2015. Isolation, characterization, kinetics, and enzymatic and nonenzymatic microbicidal activities of a novel c-type lysozyme from plasma of Schistocerca gregaria (Orthoptera: Acrididae). J Insect Sci 15.

Elrod-Erickson, M., Mishra, S., Schneider, D., 2000. Interactions between the cellular and humoral immune responses in Drosophila. Curr Biol 10, 781-784.

Estevez-Lao, T.Y., Hillyer, J.F., 2014. Involvement of the Anopheles gambiae Nimrod gene family in mosquito immune responses. Insect Biochem Mol Biol 44, $12-22$.

Evans, J.D., Aronstein, K., Chen, Y.P., Hetru, C., Imler, J.L., Jiang, H., Kanost, M., Thompson, G.J., Zou, Z., Hultmark, D., 2006. Immune pathways and defence mechanisms in honey bees Apis mellifera. Insect Mol Biol 15, 645-656.

Feir, D., O'Connor, G.M., Jr., 1965. Mitotic activity in the hemocytes of Oncopeltus fasciatus (Dall). Exp Cell Res 39, 637-642.

Ferrandon, D., Jung, A.C., Criqui, M., Lemaitre, B., Uttenweiler-Joseph, S., Michaut, L., Reichhart, J., Hoffmann, J.A., 1998. A drosomycin-GFP reporter transgene reveals a local immune response in Drosophila that is not dependent on the Toll pathway. EMBO J 17, 1217-1227.

Fraiture, M., Baxter, R.H., Steinert, S., Chelliah, Y., Frolet, C., Quispe-Tintaya, W., Hoffmann, J.A., Blandin, S.A., Levashina, E.A., 2009. Two mosquito LRR proteins function as complement control factors in the TEP1-mediated killing of Plasmodium. Cell Host Microbe 5, 273-284.

Gandhe, A.S., John, S.H., Nagaraju, J., 2007. Noduler, a novel immune up-regulated protein mediates nodulation response in insects. J Immunol 179, 6943-6951.

Gardiner, E.M., Strand, M.R., 2000. Hematopoiesis in larval Pseudoplusia includens and Spodoptera frugiperda. Arch Insect Biochem Physiol 43, 147-164.

Georgel, P., Naitza, S., Kappler, C., Ferrandon, D., Zachary, D., Swimmer, C., Kopczynski, C., Duyk, G., Reichhart, J.M., Hoffmann, J.A., 2001. Drosophila immune deficiency (IMD) is a death domain protein that activates antibacterial defense and can promote apoptosis. Dev Cell 1, 503-514.

Gerardo, N.M., Altincicek, B., Anselme, C., Atamian, H., Barribeau, S.M., de Vos, M., Duncan, E.J., Evans, J.D., Gabaldon, T., Ghanim, M., Heddi, A., Kaloshian, I., Latorre, A., Moya, A., Nakabachi, A., Parker, B.J., Perez-Brocal, V., Pignatelli, M., Rahbe, Y., Ramsey, J.S., Spragg, C.J., Tamames, J., Tamarit, D., Tamborindeguy, C., Vincent-Monegat, C., Vilcinskas, A., 2010. Immunity and other defenses in pea aphids, Acyrthosiphon pisum. Genome Biol 11, R21.

Gerould, J., 1933. Orders of insects with heart-beat reversal. Biol Bull 64, 424-431.

Gesellchen, V., Kuttenkeuler, D., Steckel, M., Pelte, N., Boutros, M., 2005. An RNA interference screen identifies Inhibitor of Apoptosis Protein 2 as a regulator of innate immune signalling in Drosophila. EMBO Rep 6, 979-984.

Ghosh, S., Singh, A., Mandal, S., Mandal, L., 2015. Active hematopoietic hubs in Drosophila adults generate hemocytes and contribute to immune response. Dev Cell 33, 478-488.

Glenn, J.D., King, J.G., Hillyer, J.F., 2010. Structural mechanics of the mosquito heart and its function in bidirectional hemolymph transport. J Exp Biol 213, 541-550.

Gonzalez-Tokman, D.M., Gonzalez-Santoyo, I., Lanz-Mendoza, H., Aguilar, A.C., 2010. Territorial damselflies do not show immunological priming in the wild. Physiol Entomol 35, 364-372.

Gullan, P.J., Cranston, P.S., 2014. The insects: an outline of entomology, 5th ed. John Wiley \& Sons, West Sussex UK. 
Gupta, L., Molina-Cruz, A., Kumar, S., Rodrigues, J., Dixit, R., Zamora, R.E., Barillas-Mury, C., 2009. The STAT pathway mediates late-phase immunity against Plasmodium in the mosquito Anopheles gambiae. Cell Host Microbe 5, 498-507.

Ha, E.M., Oh, C.T., Bae, Y.S., Lee, W.J., 2005. A direct role for dual oxidase in Drosophila gut immunity. Science 310, 847-850.

He, Y., Cao, X., Li, K., Hu, Y., Chen, Y.R., Blissard, G., Kanost, M.R., Jiang, H., 2015. A genome-wide analysis of antimicrobial effector genes and their transcription patterns in Manduca sexta. Insect Biochem Mol Biol 62, 23-37.

Hertel, W., Pass, G., 2002. An evolutionary treatment of the morphology and physiology of circulatory organs in insects. Comp Biochem Physiol A Mol Integr Physiol 133, 555-575.

Hillyer, J.F., 2010. Mosquito immunity. Adv Exp Med Biol 708, 218-238.

Hillyer, J.F., 2015. Integrated immune and cardiovascular function in Pancrustacea: Lessons from the insects. Integr Comp Biol 55, 843-855.

Hillyer, J.F., Barreau, C., Vernick, K.D., 2007. Efficiency of salivary gland invasion by malaria sporozoites is controlled by rapid sporozoite destruction in the mosquito haemocoel. Int J Parasitol 37, 673-681.

Hillyer, J.F., Christensen, B.M., 2002. Characterization of hemocytes from the yellow fever mosquito, Aedes aegypti. Histochem Cell Biol 117, 431-440.

Hillyer, J.F., Christensen, B.M., 2005. Mosquito phenoloxidase and defensin colocalize in melanization innate immune responses. J Histochem Cytochem 53, 689-698.

Hillyer, J.F., Estevez-Lao, T.Y., 2010. Nitric oxide is an essential component of the hemocytemediated mosquito immune response against bacteria. Dev Comp Immunol 34, 141 149.

Hillyer, J.F., Schmidt, S.L., Christensen, B.M., 2003a. Hemocyte-mediated phagocytosis and melanization in the mosquito Armigeres subalbatus following immune challenge by bacteria. Cell Tissue Res 313, 117-127.

Hillyer, J.F., Schmidt, S.L., Christensen, B.M., 2003b. Rapid phagocytosis and melanization of bacteria and Plasmodium sporozoites by hemocytes of the mosquito Aedes aegypti. J Parasitol 89, 62-69.

Hillyer, J.F., Schmidt, S.L., Fuchs, J.F., Boyle, J.P., Christensen, B.M., 2005. Age-associated mortality in immune challenged mosquitoes (Aedes aegypti) correlates with a decrease in haemocyte numbers. Cell Microbiol 7, 39-51.

Hillyer, J.F., Strand, M.R., 2014. Mosquito hemocyte-mediated immune responses. Curr Opin Insect Sci 3, 14-21.

Hoffmann, J.A., Hoffmann, D., 1990. The inducible antibacterial peptides of dipteran insects. Res Immunol 141, 910-918.

Holz, A., Bossinger, B., Strasser, T., Janning, W., Klapper, R., 2003. The two origins of hemocytes in Drosophila. Development 130, 4955-4962.

Honti, V., Csordas, G., Kurucz, E., Markus, R., Ando, I., 2014. The cell-mediated immunity of Drosophila melanogaster. hemocyte lineages, immune compartments, microanatomy and regulation. Dev Comp Immunol 42, 47-56.

Honti, V., Csordas, G., Markus, R., Kurucz, E., Jankovics, F., Ando, I., 2010. Cell lineage tracing reveals the plasticity of the hemocyte lineages and of the hematopoietic compartments in Drosophila melanogaster. Mol Immunol 47, 1997-2004.

Horn, L., Leips, J., Starz-Gaiano, M., 2014. Phagocytic ability declines with age in adult Drosophila hemocytes. Aging Cell 13, 719-728.

Hughes, M.N., 2008. Chemistry of nitric oxide and related species. Methods Enzymol 436, 3-19.

Hustert, R., Frisch, M., Bohm, A., Pass, G., 2014. A new kind of auxiliary heart in insects: functional morphology and neuronal control of the accessory pulsatile organs of the cricket ovipositor. Front Zool 11, 43. 
Imler, J.L., 2014. Overview of Drosophila immunity: a historical perspective. Dev Comp Immunol 42, 3-15.

Ito, Y., Nakamura, M., Hotani, T., Imoto, T., 1995. Insect lysozyme from house fly (Musca domestica) larvae: possible digestive function based on sequence and enzymatic properties. J Biochem 118, 546-551.

Jiang, H., Vilcinskas, A., Kanost, M.R., 2010. Immunity in lepidopteran insects. Adv Exp Med Biol 708, 181-204.

Jung, S.H., Evans, C.J., Uemura, C., Banerjee, U., 2005. The Drosophila lymph gland as a developmental model of hematopoiesis. Development 132, 2521-2533.

Kajla, M.K., Shi, L., Li, B., Luckhart, S., Li, J., Paskewitz, S.M., 2011. A new role for an old antimicrobial: lysozyme c-1 can function to protect malaria parasites in Anopheles mosquitoes. PLoS One 6, e19649.

Karlikow, M., Goic, B., Saleh, M.C., 2014. RNAi and antiviral defense in Drosophila: setting up a systemic immune response. Dev Comp Immunol 42, 85-92.

Kato, N., Mueller, C.R., Fuchs, J.F., McElroy, K., Wessely, V., Higgs, S., Christensen, B.M., 2008. Evaluation of the function of a type I peritrophic matrix as a physical barrier for midgut epithelium invasion by mosquito-borne pathogens in Aedes aegypti. Vector Borne Zoonotic Dis 8, 701-712.

Kaunisto, S., Harkonen, L., Rantala, M.J., Kortet, R., 2015. Early-life temperature modifies adult encapsulation response in an invasive ectoparasite. Parasitology 142, 1290-1296.

Kim, J.H., Min, J.S., Kang, J.S., Kwon, D.H., Yoon, K.S., Strycharz, J., Koh, Y.H., Pittendrigh, B.R., Clark, J.M., Lee, S.H., 2011. Comparison of the humoral and cellular immune responses between body and head lice following bacterial challenge. Insect Biochem Mol Biol 41, 332-339.

King, J.G., Hillyer, J.F., 2012. Infection-induced interaction between the mosquito circulatory and immune systems. PLoS Pathog 8, e1003058.

King, J.G., Hillyer, J.F., 2013. Spatial and temporal in vivo analysis of circulating and sessile immune cells in mosquitoes: hemocyte mitosis following infection. BMC Biol 11, 55.

Kingsolver, M.B., Huang, Z., Hardy, R.W., 2013. Insect antiviral innate immunity: pathways, effectors, and connections. J Mol Biol 425, 4921-4936.

Kleino, A., Silverman, N., 2014. The Drosophila IMD pathway in the activation of the humoral immune response. Dev Comp Immunol 42, 25-35.

Kocks, C., Cho, J.H., Nehme, N., Ulvila, J., Pearson, A.M., Meister, M., Strom, C., Conto, S.L., Hetru, C., Stuart, L.M., Stehle, T., Hoffmann, J.A., Reichhart, J.M., Ferrandon, D., Ramet, M., Ezekowitz, R.A., 2005. Eater, a transmembrane protein mediating phagocytosis of bacterial pathogens in Drosophila. Cell 123, 335-346.

Krautz, R., Arefin, B., Theopold, U., 2014. Damage signals in the insect immune response. Front Plant Sci 5, 342.

Kuraishi, T., Binggeli, O., Opota, O., Buchon, N., Lemaitre, B., 2011. Genetic evidence for a protective role of the peritrophic matrix against intestinal bacterial infection in Drosophila melanogaster. Proc Natl Acad Sci U S A 108, 15966-15971.

Kurucz, E., Markus, R., Zsamboki, J., Folkl-Medzihradszky, K., Darula, Z., Vilmos, P., Udvardy, A., Krausz, I., Lukacsovich, T., Gateff, E., Zettervall, C.J., Hultmark, D., Ando, I., 2007. Nimrod, a putative phagocytosis receptor with EGF repeats in Drosophila plasmatocytes. Curr Biol 17, 649-654.

Kwon, H., Bang, K., Cho, S., 2014a. Characterization of the hemocytes in larvae of Protaetia brevitarsis seulensis: involvement of granulocyte-mediated phagocytosis. PLoS One 9, e103620.

Kwon, H., Bang, K., Lee, M., Cho, S., 2014b. Molecular cloning and characterization of a lysozyme cDNA from the mole cricket Gryllotalpa orientalis (Orthoptera: Gryllotalpidae). Mol Biol Rep 41, 5745-5754. 
Lai, S.C., Chen, C.C., Hou, R.F., 2001. Electron microscopic observations on wound-healing in larvae of the mosquito Armigeres subalbatus (Diptera: Culicidae). J Med Entomol 38, 836-843.

Lamiable, O., Imler, J.L., 2014. Induced antiviral innate immunity in Drosophila. Curr Opin Microbiol 20, 62-68.

Lanot, R., Zachary, D., Holder, F., Meister, M., 2001. Postembryonic hematopoiesis in Drosophila. Dev Biol 230, 243-257.

Larsen, W.J., 1976. Cell remodeling in the fat body of an insect. Tissue Cell 8, 73-92.

Laughton, A.M., Garcia, J.R., Altincicek, B., Strand, M.R., Gerardo, N.M., 2011. Characterisation of immune responses in the pea aphid, Acyrthosiphon pisum. J Insect Physiol 57, 830-839.

Lavine, M.D., Strand, M.R., 2002. Insect hemocytes and their role in immunity. Insect Biochem Mol Biol 32, 1295-1309.

Lazzaro, B.P., Flores, H.A., Lorigan, J.G., Yourth, C.P., 2008. Genotype-by-environment interactions and adaptation to local temperature affect immunity and fecundity in Drosophila melanogaster. PLoS Pathog 4, e1000025.

League, G.P., Onuh, O.C., Hillyer, J.F., 2015. Comparative structural and functional analysis of the larval and adult dorsal vessel and its role in hemolymph circulation in the mosquito Anopheles gambiae. J Exp Biol 218, 370-380.

Lee, J.E., Edery, I., 2008. Circadian regulation in the ability of Drosophila to combat pathogenic infections. Curr Biol 18, 195-199.

Lee, W.K., Socha, J.J., 2009. Direct visualization of hemolymph flow in the heart of a grasshopper (Schistocerca americana). BMC Physiol 9, 2.

Lehane, M.J., Wu, D., Lehane, S.M., 1997. Midgut-specific immune molecules are produced by the blood-sucking insect Stomoxys calcitrans. Proc Natl Acad Sci U S A 94, 1150211507.

Lehmacher, C., Togel, M., Pass, G., Paululat, A., 2009. The Drosophila wing hearts consist of syncytial muscle cells that resemble adult somatic muscles. Arthropod Struct Dev 38, 111-123.

Leitao, A.B., Sucena, E., 2015. Drosophila sessile hemocyte clusters are true hematopoietic tissues that regulate larval blood cell differentiation. Elife 4, e06166.

Lemaitre, B., Hoffmann, J., 2007. The host defense of Drosophila melanogaster. Annu Rev Immunol 25, 697-743.

Levashina, E.A., Moita, L.F., Blandin, S., Vriend, G., Lagueux, M., Kafatos, F.C., 2001. Conserved role of a complement-like protein in phagocytosis revealed by dsRNA knockout in cultured cells of the mosquito, Anopheles gambiae. Cell 104, 709-718.

Li, B., Paskewitz, S.M., 2006. A role for lysozyme in melanization of Sephadex beads in Anopheles gambiae. J Insect Physiol 52, 936-942.

Lim, J., Gowda, D.C., Krishnegowda, G., Luckhart, S., 2005. Induction of nitric oxide synthase in Anopheles stephensi by Plasmodium falciparum: mechanism of signaling and the role of parasite glycosylphosphatidylinositols. Infect Immun 73, 2778-2789.

Lindsay, S.A., Wasserman, S.A., 2014. Conventional and non-conventional Drosophila Toll signaling. Dev Comp Immunol 42, 16-24.

Luckhart, S., Vodovotz, Y., Cui, L., Rosenberg, R., 1998. The mosquito Anopheles stephensi limits malaria parasite development with inducible synthesis of nitric oxide. Proc Natl Acad Sci U S A 95, 5700-5705.

Lundgren, J.G., Jurat-Fuentes, J.L., 2012. Physiology and ecology of host defense against microbial invaders, in: Vega, F.E., Kaya, H.K. (Eds.), Insect Pathology, 2nd ed. Academic Press, London UK, pp. 461-480.

Mackenzie, D.K., Bussiere, L.F., Tinsley, M.C., 2011. Senescence of the cellular immune response in Drosophila melanogaster. Exp Gerontol 46, 853-859. 
Mahy, B.W.J., 2004. Vector-borne diseases, in: Gillespie, S.H., Smith, G.L., Osbourn, A. (Eds.), Microbe-vector interactions in vector-borne diseases. Cambridge University Press, Cambridge UK, pp. 1-18.

Mamali, I., Lamprou, I., Karagiannis, F., Karakantza, M., Lampropoulou, M., Marmaras, V.J., 2009. A beta integrin subunit regulates bacterial phagocytosis in medfly haemocytes. Dev Comp Immunol 33, 858-866.

Mangalika, P.R., Kawamoto, T., Takahashi-Nakaguchi, A., Iwabuchi, K., 2010. Characterization of cell clusters in larval hemolymph of the cabbage armyworm Mamestra brassicae and their role in maintenance of hemocyte populations. J Insect Physiol 56, 314-323.

Manguin, S., Carnevale, P., Mouchet, J., 2008. Biodiversity of malaria in the world. John Libbey Eurotext, Esther UK.

Markus, R., Laurinyecz, B., Kurucz, E., Honti, V., Bajusz, I., Sipos, B., Somogyi, K., Kronhamn, J., Hultmark, D., Ando, I., 2009. Sessile hemocytes as a hematopoietic compartment in Drosophila melanogaster. Proc Natl Acad Sci U S A 106, 4805-4809.

Martins, G.F., Serrao, J.E., Ramalho-Ortigao, J.M., Pimenta, P.F., 2011. A comparative study of fat body morphology in five mosquito species. Mem Inst Oswaldo Cruz 106, 742-747.

Masri, L., Cremer, S., 2014. Individual and social immunisation in insects. Trends Immunol 35, 471-482.

Matskevich, A.A., Quintin, J., Ferrandon, D., 2010. The Drosophila PRR GNBP3 assembles effector complexes involved in antifungal defenses independently of its Toll-pathway activation function. Eur J Immunol 40, 1244-1254.

McGreevy, P.B., Bryan, J.H., Oothuman, P., Kolstrup, N., 1978. The lethal effects of the cibarial and pharyngeal armatures of mosquitoes on microfilariae. Trans R Soc Trop Med Hyg 72, 361-368.

Mesquita, R.D., Vionette-Amaral, R.J., Lowenberger, C., Rivera-Pomar, R., Monteiro, F.A., Minx, P., Spieth, J., Carvalho, A.B., Panzera, F., Lawson, D., Torres, A.Q., Ribeiro, J.M.C., Sorgine, M.H.F., Waterhouse, R.M., Montague, M.J., Abad-Franch, F., AlvesBezerra, M., Amaral, L.R., Araujo, H.M., Araujo, R.N., Aravind, L., Atella, G.C., Azambuja, P., Berni, M., Bittencourt-Cunha, P.R., Braz, G.R.C., Calderón-Fernández, G., Carareto, C.M.A., Christensen, M.B., Costa, I.R., Costa, S.G., Dansa, M., DaumasFilho, C.R.O., De-Paula, I.F., Dias, F.A., Dimopoulos, G., Emrich, S.J., EspondaBehrens, N., Fampa, P., Fernandez-Medina, R.D., da Fonseca, R.N., Fontenele, M., Fronick, C., Fulton, L.A., Gandara, A.C., Garcia, E.S., Genta, F.A., Giraldo-Calderón, G.I., Gomes, B., Gondim, K.C., Granzotto, A., Guarneri, A.A., Guigó, R., Harry, M., Hughes, D.S.T., Jablonka, W., Jacquin-Joly, E., Juárez, M.P., Koerich, L.B., LatorreEstivalis, J.M., Lavore, A., Lawrence, G.G., Lazoski, C., Lazzari, C.R., Lopes, R.R., Lorenzo, M.G., Lugon, M.D., Majerowicz, D., Marcet, P.L., Mariotti, M., Masuda, H., Megy, K., Melo, A.C.A., Missirlis, F., Mota, T., Noriega, F.G., Nouzova, M., Nunes, R.D., Oliveira, R.L.L., Oliveira-Silveira, G., Ons, S., Pagola, L., Paiva-Silva, G.O., Pascual, A., Pavan, M.G., Pedrini, N., Peixoto, A.A., Pereira, M.H., Pike, A., Polycarpo, C., Prosdocimi, F., Ribeiro-Rodrigues, R., Robertson, H.M., Salerno, A.P., Salmon, D., Santesmasses, D., Schama, R., Seabra-Junior, E.S., Silva-Cardoso, L., Silva-Neto, M.A.C., Souza-Gomes, M., Sterkel, M., Taracena, M.L., Tojo, M., Tu, Z.J., Tubio, J.M.C., Ursic-Bedoya, R., Venancio, T.M., Walter-Nuno, A.B., Wilson, D., Warren, W.C., Wilson, R.K., Huebner, E., Dotson, E.M., Oliveira, P.L., 2015. Genome of Rhodnius prolixus, an insect vector of Chagas disease, reveals unique adaptations to hematophagy and parasite infection. Proc Natl Acad Sci U S A 112, 14936-14941.

Meunier, J., 2015. Social immunity and the evolution of group living in insects. Philos Trans $R$ Soc Lond B Biol Sci 370.

Misof, B., Liu, S., Meusemann, K., Peters, R.S., Donath, A., Mayer, C., Frandsen, P.B., Ware, J., Flouri, T., Beutel, R.G., Niehuis, O., Petersen, M., Izquierdo-Carrasco, F., Wappler, 
T., Rust, J., Aberer, A.J., Aspock, U., Aspock, H., Bartel, D., Blanke, A., Berger, S., Bohm, A., Buckley, T.R., Calcott, B., Chen, J., Friedrich, F., Fukui, M., Fujita, M., Greve, C., Grobe, P., Gu, S., Huang, Y., Jermiin, L.S., Kawahara, A.Y., Krogmann, L., Kubiak, M., Lanfear, R., Letsch, H., Li, Y., Li, Z., Li, J., Lu, H., Machida, R., Mashimo, Y., Kapli, P., McKenna, D.D., Meng, G., Nakagaki, Y., Navarrete-Heredia, J.L., Ott, M., Ou, Y., Pass, G., Podsiadlowski, L., Pohl, H., von Reumont, B.M., Schutte, K., Sekiya, K., Shimizu, S., Slipinski, A., Stamatakis, A., Song, W., Su, X., Szucsich, N.U., Tan, M., Tan, X., Tang, M., Tang, J., Timelthaler, G., Tomizuka, S., Trautwein, M., Tong, X., Uchifune, T., Walzl, M.G., Wiegmann, B.M., Wilbrandt, J., Wipfler, B., Wong, T.K., Wu, Q., Wu, G., Xie, Y., Yang, S., Yang, Q., Yeates, D.K., Yoshizawa, K., Zhang, Q., Zhang, R., Zhang, W., Zhang, Y., Zhao, J., Zhou, C., Zhou, L., Ziesmann, T., Zou, S., Li, Y., Xu, X., Zhang, Y., Yang, H., Wang, J., Wang, J., Kjer, K.M., Zhou, X., 2014. Phylogenomics resolves the timing and pattern of insect evolution. Science 346, 763-767.

Moita, L.F., Wang-Sattler, R., Michel, K., Zimmermann, T., Blandin, S., Levashina, E.A., Kafatos, F.C., 2005. In vivo identification of novel regulators and conserved pathways of phagocytosis in A. gambiae. Immunity 23, 65-73.

Monpeyssin, M., Beaulaton, J., 1978. Hemocytopoiesis in the oak silkworm Antheraea pernyi and some other lepidoptera. I. Ultrastructural study of normal processes. J Ultrastruct Res 64, 35-45.

Moret, Y., Schmid-Hempel, P., 2001. Immune defence in bumble-bee offspring. Nature 414, 506.

Moret, Y., Siva-Jothy, M.T., 2003. Adaptive innate immunity? Responsive-mode prophylaxis in the mealworm beetle, Tenebrio molitor. Proc Biol Sci 270, 2475-2480.

Mostafa, A.M., Fields, P.G., Holliday, N.J., 2005. Effect of temperature and relative humidity on the cellular defense response of Ephestia kuehniella larvae fed Bacillus thuringiensis. J Invertebr Pathol 90, 79-84.

Moy, R.H., Cherry, S., 2013. Antimicrobial autophagy: a conserved innate immune response in Drosophila. J Innate Immun 5, 444-455.

Moy, R.H., Gold, B., Molleston, J.M., Schad, V., Yanger, K., Salzano, M.V., Yagi, Y., Fitzgerald, K.A., Stanger, B.Z., Soldan, S.S., Cherry, S., 2014. Antiviral autophagy restricts Rift Valley fever virus infection and is conserved from flies to mammals. Immunity 40, 51-65.

Murdock, C.C., Paaijmans, K.P., Cox-Foster, D., Read, A.F., Thomas, M.B., 2012. Rethinking vector immunology: the role of environmental temperature in shaping resistance. Nat Rev Microbiol 10, 869-876.

Murphy, K., 2011. Janeway's Immunobiology, 8th ed. Garland Science, New York.

Myllymaki, H., Ramet, M., 2014. JAK/STAT pathway in Drosophila immunity. Scand J Immunol 79, 377-385.

Nainu, F., Tanaka, Y., Shiratsuchi, A., Nakanishi, Y., 2015. Protection of insects against viral infection by apoptosis-dependent phagocytosis. J Immunol DOI: 10.4049/jimmunol.1500613.

Nakahara, Y., Kanamori, Y., Kiuchi, M., Kamimura, M., 2003. In vitro studies of hematopoiesis in the silkworm: cell proliferation in and hemocyte discharge from the hematopoietic organ. J Insect Physiol 49, 907-916.

Nakahara, Y., Matsumoto, H., Kanamori, Y., Kataoka, H., Mizoguchi, A., Kiuchi, M., Kamimura, M., 2006. Insulin signaling is involved in hematopoietic regulation in an insect hematopoietic organ. J Insect Physiol 52, 105-111.

Nappi, A.J., Christensen, B.M., 2005. Melanogenesis and associated cytotoxic reactions: applications to insect innate immunity. Insect Biochem Mol Biol 35, 443-459.

Nappi, A.J., Vass, E., Frey, F., Carton, Y., 2000. Nitric oxide involvement in Drosophila immunity. Nitric Oxide 4, 423-430. 
Nardi, J.B., 2004. Embryonic origins of the two main classes of hemocytes--granular cells and plasmatocytes--in Manduca sexta. Dev Genes Evol 214, 19-28.

Nardi, J.B., Pilas, B., Ujhelyi, E., Garsha, K., Kanost, M.R., 2003. Hematopoietic organs of Manduca sexta and hemocyte lineages. Dev Genes Evol 213, 477-491.

Oliver, J.D., Dusty Loy, J., Parikh, G., Bartholomay, L., 2011. Comparative analysis of hemocyte phagocytosis between six species of arthropods as measured by flow cytometry. $\mathrm{J}$ Invertebr Pathol 108, 126-130.

Ortiz-Urquiza, A., Luo, Z., Keyhani, N.O., 2015. Improving mycoinsecticides for insect biological control. Appl Microbiol Biotechnol 99, 1057-1068.

Osta, M.A., Christophides, G.K., Kafatos, F.C., 2004. Effects of mosquito genes on Plasmodium development. Science 303, 2030-2032.

Pakpour, N., Riehle, M.A., Luckhart, S., 2014. Effects of ingested vertebrate-derived factors on insect immune responses. Curr Opin Insect Sci 3, 1-5.

Palmer, W.J., Jiggins, F.M., 2015. Comparative genomics reveals the origins and diversity of arthropod immune systems. Mol Biol Evol 32, 2111-2129.

Paradkar, P.N., Trinidad, L., Voysey, R., Duchemin, J.B., Walker, P.J., 2012. Secreted Vago restricts West Nile virus infection in Culex mosquito cells by activating the Jak-STAT pathway. Proc Natl Acad Sci U S A 109, 18915-18920.

Park, J.W., Kim, C.H., Rui, J., Park, K.H., Ryu, K.H., Chai, J.H., Hwang, H.O., Kurokawa, K., Ha, N.C., Soderhill, I., Soderhill, K., Lee, B.L., 2010. Beetle immunity. Adv Exp Med Biol 708, 163-180.

Park, Y., Kim, Y., Stanley, D., 2011. Cellular immunosenescence in adult male crickets, Gryllus assimilis. Arch Insect Biochem Physiol 76, 185-194.

Patel, R.K., Hardy, R.W., 2012. Role for the phosphatidylinositol 3-kinase-Akt-TOR pathway during sindbis virus replication in arthropods. J Virol 86, 3595-3604.

Paulson, S.L., Grimstad, P.R., 1989. Replication and dissemination of La Crosse virus in the competent vector Aedes triseriatus and the incompetent vector Aedes hendersoni and evidence for transovarial transmission by Aedes hendersoni (Diptera: Culicidae). J Med Entomol 26, 602-609.

Pech, L.L., Strand, M.R., 1995. Encapsulation of foreign targets by hemocytes of the moth Pseudoplusia includens (Lepidoptera, Noctuidae) Involves an RGD-dependent celladhesion mechanism. J Insect Physiol 41, 481-488.

Pech, L.L., Strand, M.R., 1996. Granular cells are required for encapsulation of foreign targets by insect haemocytes. J Cell Sci 109, 2053-2060.

Pedrini, N., Crespo, R., Juarez, M.P., 2007. Biochemistry of insect epicuticle degradation by entomopathogenic fungi. Comp Biochem Physiol C Toxicol Pharmacol 146, 124-137.

Pennacchio, F., Strand, M.R., 2006. Evolution of developmental strategies in parasitic Hymenoptera. Annu Rev Entomol 51, 233-258.

Pereira, M.F., Rossi, C.C., de Queiroz, M.V., Martins, G.F., Isaac, C., Bossé, J.T., Li, Y., Wren, B.W., Terra, V.S., Cuccui, J., Langford, P.R., Bazzolli, D.M., 2015. Galleria mellonella is an effective model to study Actinobacillus pleuropneumoniae infection. Microbiology 161, 387-400.

Pham, L.N., Dionne, M.S., Shirasu-Hiza, M., Schneider, D.S., 2007. A specific primed immune response in Drosophila is dependent on phagocytes. PLoS Pathog 3, e26.

Pigeault, R., Nicot, A., Gandon, S., Rivero, A., 2015. Mosquito age and avian malaria infection. Malar J 14, 383.

Pinto, S.B., Kafatos, F.C., Michel, K., 2008. The parasite invasion marker SRPN6 reduces sporozoite numbers in salivary glands of Anopheles gambiae. Cell Microbiol 10, 891898.

Prasai, K., Karlsson, B., 2012. Variation in immune defence in relation to age in the greenveined white butterfly (Pieris napi L.). J Invertebr Pathol 111, 252-254. 
Ramet, M., Manfruelli, P., Pearson, A., Mathey-Prevot, B., Ezekowitz, R.A., 2002. Functional genomic analysis of phagocytosis and identification of a Drosophila receptor for $E$. coli. Nature 416, 644-648.

Rao, X.J., Ling, E., Yu, X.Q., 2010. The role of lysozyme in the prophenoloxidase activation system of Manduca sexta: an in vitro approach. Dev Comp Immunol 34, 264-271.

Ratcliffe, N.A., Gagen, S.J., 1977. Studies on the in vivo cellular reactions of insects: an ultrastructural analysis of nodule formation in Galleria mellonella. Tissue Cell 9, 73-85.

Reavey, C.E., Beare, L., Cotter, S.C., 2014. Parental care influences social immunity in burying beetle larvae. Ecol Entomol 39, 395-398.

Reber, A., Chapuisat, M., 2012. No evidence for immune priming in ants exposed to a fungal pathogen. PLoS One 7, e35372.

Reidenbach, K.R., Cook, S., Bertone, M.A., Harbach, R.E., Wiegmann, B.M., Besansky, N.J., 2009. Phylogenetic analysis and temporal diversification of mosquitoes (Diptera: Culicidae) based on nuclear genes and morphology. BMC Evol Biol 9, 298.

Ribeiro, C., Brehelin, M., 2006. Insect haemocytes: what type of cell is that? J Insect Physiol 52, 417-429.

Robb, T., Forbes, M.R., 2006. Age-dependent induction of immunity and subsequent survival costs in males and females of a temperate damselfly. BMC Ecol 6, 15.

Roberts, K.E., Hughes, W.O., 2014. Immunosenescence and resistance to parasite infection in the honey bee, Apis mellifera. J Invertebr Pathol 121, 1-6.

Roberts, L.S., Janovy Jr., J., Nadler, S., 2013. Foundations of Parasitology. McGraw-Hill, New York NY USA.

Rodrigues, J., Brayner, F.A., Alves, L.C., Dixit, R., Barillas-Mury, C., 2010. Hemocyte differentiation mediates innate immune memory in Anopheles gambiae mosquitoes. Science 329, 1353-1355.

Rosengaus, R.B., Malak, T., Mackintosh, C., 2013. Immune-priming in ant larvae: social immunity does not undermine individual immunity. Biol Lett 9, 20130563.

Roth, O., Sadd, B.M., Schmid-Hempel, P., Kurtz, J., 2009. Strain-specific priming of resistance in the red flour beetle, Tribolium castaneum. Proc Biol Sci 276, 145-151.

Rowley, A.F., Ratcliffe, N.A., 1978. A histological study of wound healing and hemocyte function in the wax-moth Galleria mellonella. J Morphol 157, 181-199.

Rozen, D.E., Engelmoer, D.J., Smiseth, P.T., 2008. Antimicrobial strategies in burying beetles breeding on carrion. Proc Natl Acad Sci U S A 105, 17890-17895.

Russo, J., Dupas, S., Frey, F., Carton, Y., Brehelin, M., 1996. Insect immunity: early events in the encapsulation process of parasitoid (Leptopilina boulardi) eggs in resistant and susceptible strains of Drosophila. Parasitology 112 ( Pt 1), 135-142.

Sackton, T.B., Lazzaro, B.P., Schlenke, T.A., Evans, J.D., Hultmark, D., Clark, A.G., 2007. Dynamic evolution of the innate immune system in Drosophila. Nat Genet 39, 14611468.

Sadd, B.M., Schmid-Hempel, P., 2006. Insect immunity shows specificity in protection upon secondary pathogen exposure. Curr Biol 16, 1206-1210.

Satyavathi, V.V., Minz, A., Nagaraju, J., 2014. Nodulation: an unexplored cellular defense mechanism in insects. Cell Signal 26, 1753-1763.

Satyavathi, V.V., Narra, D., Nagaraju, J., 2015. Noduler an immune protein augments infectioninduced cell proliferation through cross-talking with p38 MAPK. Immunobiology DOI: 10.1016/j.imbio.2015.09.018.

Schmid, M.R., Anderl, I., Vesala, L., Vanha-aho, L.M., Deng, X.J., Ramet, M., Hultmark, D., 2014. Control of Drosophila blood cell activation via Toll signaling in the fat body. PLoS One 9 , e102568. 
Schmid, M.R., Brockmann, A., Pirk, C.W., Stanley, D.W., Tautz, J., 2008. Adult honeybees (Apis mellifera L.) abandon hemocytic, but not phenoloxidase-based immunity. J Insect Physiol 54, 439-444.

Schmitz, A., Anselme, C., Ravallec, M., Rebuf, C., Simon, J.C., Gatti, J.L., Poirie, M., 2012. The cellular immune response of the pea aphid to foreign intrusion and symbiotic challenge. PLoS One 7, e42114.

Scott, J.G., Michel, K., Bartholomay, L.C., Siegfried, B.D., Hunter, W.B., Smagghe, G., Zhu, K.Y., Douglas, A.E., 2013. Towards the elements of successful insect RNAi. J Insect Physiol 59, 1212-1221.

Shelly, S., Lukinova, N., Bambina, S., Berman, A., Cherry, S., 2009. Autophagy is an essential component of Drosophila immunity against vesicular stomatitis virus. Immunity 30,588 598.

Shia, A.K., Glittenberg, M., Thompson, G., Weber, A.N., Reichhart, J.M., Ligoxygakis, P., 2009. Toll-dependent antimicrobial responses in Drosophila larval fat body require Spatzle secreted by haemocytes. J Cell Sci 122, 4505-4515.

Shiao, S.H., Higgs, S., Adelman, Z., Christensen, B.M., Liu, S.H., Chen, C.C., 2001. Effect of prophenoloxidase expression knockout on the melanization of microfilariae in the mosquito Armigeres subalbatus. Insect Mol Biol 10, 315-321.

Shibutani, S.T., Saitoh, T., Nowag, H., Munz, C., Yoshimori, T., 2015. Autophagy and autophagy-related proteins in the immune system. Nat Immunol 16, 1014-1024.

Sigle, L.T., Hillyer, J.F., 2016. Mosquito hemocytes preferentially aggregate and phagocytose pathogens in the periostial regions of the heart that experience the most hemolymph flow. Dev Comp Immunol 55, 90-101.

Sim, S., Jupatanakul, N., Dimopoulos, G., 2014. Mosquito immunity against arboviruses. Viruses 6, 4479-4504.

Simone-Finstrom, M., Spivak, M., 2010. Propolis and bee health: the natural history and significance of resin use by honey bees. Apidologie 41, 295-311.

Siva-Jothy, M.T., Moret, Y., Rolff, J., 2005. Insect immunity: An evolutionary ecology perspective. Adv Insect Physiol 32, 1-48.

Slauch, J.M., 2011. How does the oxidative burst of macrophages kill bacteria? Still an open question. Mol Microbiol 80, 580-583.

Sota, T., Yamamoto, S., Cooley, J.R., Hill, K.B., Simon, C., Yoshimura, J., 2013. Independent divergence of 13- and 17-y life cycles among three periodical cicada lineages. Proc Natl Acad Sci U S A 110, 6919-6924.

Sowa-Jasilek, A., Zdybicka-Barabas, A., Staczek, S., Wydrych, J., Mak, P., Jakubowicz, T., Cytrynska, M., 2014. Studies on the role of insect hemolymph polypeptides: Galleria mellonella anionic peptide 2 and lysozyme. Peptides 53, 194-201.

Starks, P.T., Blackie, C.A., Seeley, T.D., 2000. Fever in honeybee colonies. Naturwissenschaften 87, 229-231.

Steiner, H., Hultmark, D., Engstrom, A., Bennich, H., Boman, H.G., 1981. Sequence and specificity of two antibacterial proteins involved in insect immunity. Nature 292, 246-248.

Stone, E.F., Fulton, B.O., Ayres, J.S., Pham, L.N., Ziauddin, J., Shirasu-Hiza, M.M., 2012. The circadian clock protein timeless regulates phagocytosis of bacteria in Drosophila. PLoS Pathog 8, e1002445.

Strand, M.R., 2008. The insect cellular immune response. Insect Sci 15, 1-14.

Suzanne, M., Steller, H., 2013. Shaping organisms with apoptosis. Cell Death Differ 20, 669675.

Tan, J., Xu, M., Zhang, K., Wang, X., Chen, S., Li, T., Xiang, Z., Cui, H., 2013. Characterization of hemocytes proliferation in larval silkworm, Bombyx mori. J Insect Physiol 59, 595-603.

Tauber, O.E., 1940. Mitotic response of roach hemocytes to certain pathogenes in the hemolymph. Ann Entomol Soc Am 33, 113-119. 
Thomas, A.M., Rudolf, V.H.W., 2010. Challenges of metamorphosis in invertebrate hosts: maintaining parasite resistance across life-history stages. Ecol Entomol 35, 200-205.

Traniello, J.F., Rosengaus, R.B., Savoie, K., 2002. The development of immunity in a social insect: evidence for the group facilitation of disease resistance. Proc Natl Acad Sci U S A 99, 6838-6842.

Trauer-Kizilelma, U., Hilker, M., 2015. Impact of transgenerational immune priming on the defence of insect eggs against parasitism. Dev Comp Immunol 51, 126-133.

Trautwein, M.D., Wiegmann, B.M., Beutel, R., Kjer, K.M., Yeates, D.K., 2012. Advances in insect phylogeny at the dawn of the postgenomic era. Annu Rev Entomol 57, 449-468.

Tsao, I.Y., Chen, J.W., Li, C.J., Lo, H.L., Christensen, B.M., Chen, C.C., 2015. The dual roles of Armigeres subalbatus prophenoloxidase $\mathrm{V}$ in parasite melanization and egg chorion melanization in the mosquito Ar. subalbatus. Insect Biochem Mol Biol 64, 68-77.

Tsao, I.Y., Lin, U.S., Christensen, B.M., Chen, C.C., 2009. Armigeres subalbatus prophenoloxidase III: Cloning, characterization and potential role in morphogenesis. Insect Biochem Mol Biol 39, 96-104.

Ugelvig, L.V., Cremer, S., 2007. Social prophylaxis: group interaction promotes collective immunity in ant colonies. Curr Biol 17, 1967-1971.

Ursic-Bedoya, R.J., Nazzari, H., Cooper, D., Triana, O., Wolff, M., Lowenberger, C., 2008. Identification and characterization of two novel lysozymes from Rhodnius prolixus, a vector of Chagas disease. J Insect Physiol 54, 593-603.

Vachon, V., Laprade, R., Schwartz, J.L., 2012. Current models of the mode of action of Bacillus thuringiensis insecticidal crystal proteins: a critical review. J Invertebr Pathol 111, 1-12.

Vaidyanathan, R., Scott, T.W., 2006. Apoptosis in mosquito midgut epithelia associated with West Nile virus infection. Apoptosis 11, 1643-1651.

Vega, F.E., Kaya, H.K., 2012. Insect Pathology, 2nd ed. Academic Press, London UK.

Vizioli, J., Bulet, P., Hoffmann, J.A., Kafatos, F.C., Muller, H.M., Dimopoulos, G., 2001. Gambicin: a novel immune responsive antimicrobial peptide from the malaria vector Anopheles gambiae. Proc Natl Acad Sci U S A 98, 12630-12635.

Volz, J., Muller, H.M., Zdanowicz, A., Kafatos, F.C., Osta, M.A., 2006. A genetic module regulates the melanization response of Anopheles to Plasmodium. Cell Microbiol 8, 1392-1405.

Walker, T.N., Hughes, W.O., 2009. Adaptive social immunity in leaf-cutting ants. Biol Lett 5, 446-448.

Wang, H., Gort, T., Boyle, D.L., Clem, R.J., 2012. Effects of manipulating apoptosis on Sindbis virus infection of Aedes aegypti mosquitoes. J Virol 86, 6546-6554.

Wang, J.L., Chen, L., Tang, L., Zhao, H.B., Liu, X.S., Wang, Y.F., 2014a. 20-hydroxyecdysone transcriptionally regulates humoral immunity in the fat body of Helicoverpa armigera. Insect Mol Biol 23, 842-856.

Wang, J.L., Zhang, Q., Tang, L., Chen, L., Liu, X.S., Wang, Y.F., 2014b. Involvement of a pattern recognition receptor C-type lectin 7 in enhancing cellular encapsulation and melanization due to its carboxyl-terminal CRD domain in the cotton bollworm, Helicoverpa armigera. Dev Comp Immunol 44, 21-29.

Wang, X., Fuchs, J.F., Infanger, L.C., Rocheleau, T.A., Hillyer, J.F., Chen, C.C., Christensen, B.M., 2005. Mosquito innate immunity: involvement of beta 1,3-glucan recognition protein in melanotic encapsulation immune responses in Armigeres subalbatus. Mol Biochem Parasitol 139, 65-73.

Wasserthal, L.T., 2007. Drosophila flies combine periodic heartbeat reversal with a circulation in the anterior body mediated by a newly discovered anterior pair of ostial valves and 'venous' channels'. J Exp Biol 210, 3707-3719.

Waterhouse, R.M., Kriventseva, E.V., Meister, S., Xi, Z., Alvarez, K.S., Bartholomay, L.C., Barillas-Mury, C., Bian, G., Blandin, S., Christensen, B.M., Dong, Y., Jiang, H., Kanost, 
M.R., Koutsos, A.C., Levashina, E.A., Li, J., Ligoxygakis, P., Maccallum, R.M., Mayhew, G.F., Mendes, A., Michel, K., Osta, M.A., Paskewitz, S., Shin, S.W., Vlachou, D., Wang, L., Wei, W., Zheng, L., Zou, Z., Severson, D.W., Raikhel, A.S., Kafatos, F.C., Dimopoulos, G., Zdobnov, E.M., Christophides, G.K., 2007. Evolutionary dynamics of immune-related genes and pathways in disease-vector mosquitoes. Science 316, 17381743.

Weiss, B.L., Savage, A.F., Griffith, B.C., Wu, Y., Aksoy, S., 2014. The peritrophic matrix mediates differential infection outcomes in the tsetse fly gut following challenge with commensal, pathogenic, and parasitic microbes. J Immunol 193, 773-782.

Wojda, I., Kowalski, P., Jakubowicz, T., 2004. JNK MAP kinase is involved in the humoral immune response of the greater wax moth larvae Galleria mellonella. Arch Insect Biochem Physiol 56, 143-154.

Wood, W., Jacinto, A., 2007. Drosophila melanogaster embryonic haemocytes: masters of multitasking. Nat Rev Mol Cell Biol 8, 542-551.

Wu, S.C., Liao, C.W., Pan, R.L., Juang, J.L., 2012. Infection-induced intestinal oxidative stress triggers organ-to-organ immunological communication in Drosophila. Cell Host Microbe 11, 410-417.

Xu, J., Cherry, S., 2014. Viruses and antiviral immunity in Drosophila. Dev Comp Immunol 42, 67-84.

Yano, T., Kurata, S., 2011. Intracellular recognition of pathogens and autophagy as an innate immune host defence. J Biochem 150, 143-149.

Yeates, D.K., Wiegmann, B.M., 1999. Congruence and controversy: toward a higher-level phylogeny of Diptera. Annu Rev Entomol 44, 397-428.

Yi, H.Y., Chowdhury, M., Huang, Y.D., Yu, X.Q., 2014. Insect antimicrobial peptides and their applications. Appl Microbiol Biotechnol 98, 5807-5822.

Yu, N., Christiaens, O., Liu, J., Niu, J., Cappelle, K., Caccia, S., Huvenne, H., Smagghe, G., 2013. Delivery of dsRNA for RNAi in insects: an overview and future directions. Insect Sci 20, 4-14.

Zhang, X., He, Y., Cao, X., Gunaratna, R.T., Chen, Y.R., Blissard, G., Kanost, M.R., Jiang, H., 2015. Phylogenetic analysis and expression profiling of the pattern recognition receptors: Insights into molecular recognition of invading pathogens in Manduca sexta. Insect Biochem Mol Biol 62, 38-50.

Zhao, X., Ferdig, M.T., Li, J., Christensen, B.M., 1995. Biochemical pathway of melanotic encapsulation of Brugia malayi in the mosquito, Armigeres subalbatus. Dev Comp Immunol 19, 205-215.

Zou, Z., Evans, J.D., Lu, Z., Zhao, P., Williams, M., Sumathipala, N., Hetru, C., Hultmark, D., Jiang, H., 2007. Comparative genomic analysis of the Tribolium immune system. Genome Biol 8, R177.

Zsamboki, J., Csordas, G., Honti, V., Pinter, L., Bajusz, I., Galgoczy, L., Ando, I., Kurucz, E., 2013. Drosophila Nimrod proteins bind bacteria. Cent Eur J Biol 8, 633-645. 


\section{Figure legends:}

Figure 1. Anatomy of the insect immune system. The insect body cavity, called the hemocoel, is a fluid and dynamic space that houses tissues with immune activity. The primary immune cells are the hemocytes. Hemocytes are found in circulation (circulating hemocytes) and attached to tissues (sessile hemocytes), where they phagocytose, encapsulate and nodulate pathogens, and produce humoral immune factors. The fat body, the midgut, the salivary glands, and other tissues produce numerous humoral immune factors with, among other things, lytic and melanizing activity. For a description of how hemolymph circulation impacts immune responses, and the activity of periostial hemocytes, see figure 7 .

Figure 2. Gene counts for select genes and gene families in Anopheles gambiae (Order: Diptera), Aedes aegypti (Diptera), Drosophila melanogaster (Diptera), Pediculus humanus humanus (Siphonaptera), Manduca sexta (Lepidoptera), Tribolium castaneum (Coleoptera), Apis mellifera (Hymenoptera), and Acyrthosiphon pisum (Hemiptera). The gene number data was collected from (Cao et al., 2015; Chevignon et al., 2015; Evans et al., 2006; Gerardo et al., 2010; He et al., 2015; Kim et al., 2011; Sackton et al., 2007; Waterhouse et al., 2007; Zhang et al., 2015; Zou et al., 2007), with additional searches in https://www.vectorbase.org and http://metazoa.ensembl.org. The evolutionary relationships between the species, depicted at the top of the figure, are based on (Trautwein et al., 2012). Gene numbers can vary slightly depending on the analysis. Abbreviations: PRR, pattern recognition receptor; Toll (vertical orientation), Toll pathway; Imd (vertical orientation), Imd pathway; Effector, effector peptides and proteins; PGRP, peptidoglycan recognition protein; FREP, fibrinogen-related protein; $\beta$ GRP, $\beta$-1,3 glucan recognition protein; GNBP, Gram(-) binding protein; CTL, C-type lectin; PPO, pro-phenoloxidase. 
Figure 3. Simplified diagram illustrating key players in the Toll, Imd, and Jak/Stat pathways, using mosquitoes as the example. For a description of the pathways, see section 4 .

Figure 4. Immune effector mechanisms of insects. Insects kill pathogens via phagocytosis (section 5.1), melanization (section 5.2), cellular encapsulation (section 5.3), nodulation (section 5.4), lysis (section 5.5), RNA interference (section 5.6), autophagy (section 5.7), and apoptosis (section 5.8).

Figure 5. Biochemical pathway of phenoloxidase-based melanization. For a description of the pathway, see section 5.2. Abbreviations: PRR, pattern recognition receptor; $\beta$ GRP, $\beta-1,3$ glucan recognition protein; CTL, C-type lectin; GNBP, Gram(-) binding protein; PPAE, phenoloxidase activating enzyme; PAH, phenylalanine hydroxylase; PO, phenoloxidase; DDC, dopa decarboxylase; DCE, dopachrome conversion enzyme.

Figure 6. Small interfering RNA pathway. For a description of this RNAi pathway, see section 5.6.

Figure 7. Co-adaptation of the insect circulatory and immune systems, as exemplified in mosquitoes. Hemocytes exist in two states: in circulation and in sessile form. In naïve mosquitoes (top), some of the sessile hemocytes are aggregated around the ostia (valves) of the heart, and are called periostial hemocytes. Hemolymph flow is swift in the regions surrounding the ostia (the periostial regions), and the majority of hemolymph enters the heart through the ostia located in abdominal segments 4, 5, and 6. Upon infection (bottom), circulating hemocytes undergo mitosis and increase in number, and many hemocytes migrate to, and aggregate in, the periostial regions of the heart where they phagocytose pathogens. The periostial regions are the only location of the body where sessile hemocytes increase in 
number in response to infection. Infection does not significantly alter the proportion of hemolymph that flows through each periostial region, and periostial hemocytes - including their immune activity - preferentially aggregate around the ostia that experience the most hemolymph flow. Figure from Sigle and Hillyer (Sigle and Hillyer, 2016); reproduced with permission. 


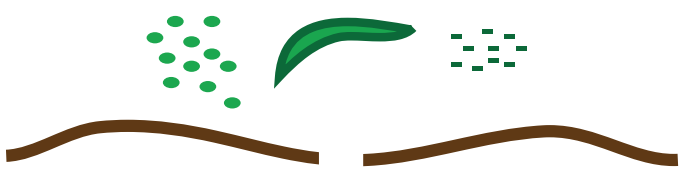

\section{$\downarrow^{\text {Infection }}$}

$$
\because \because \square
$$
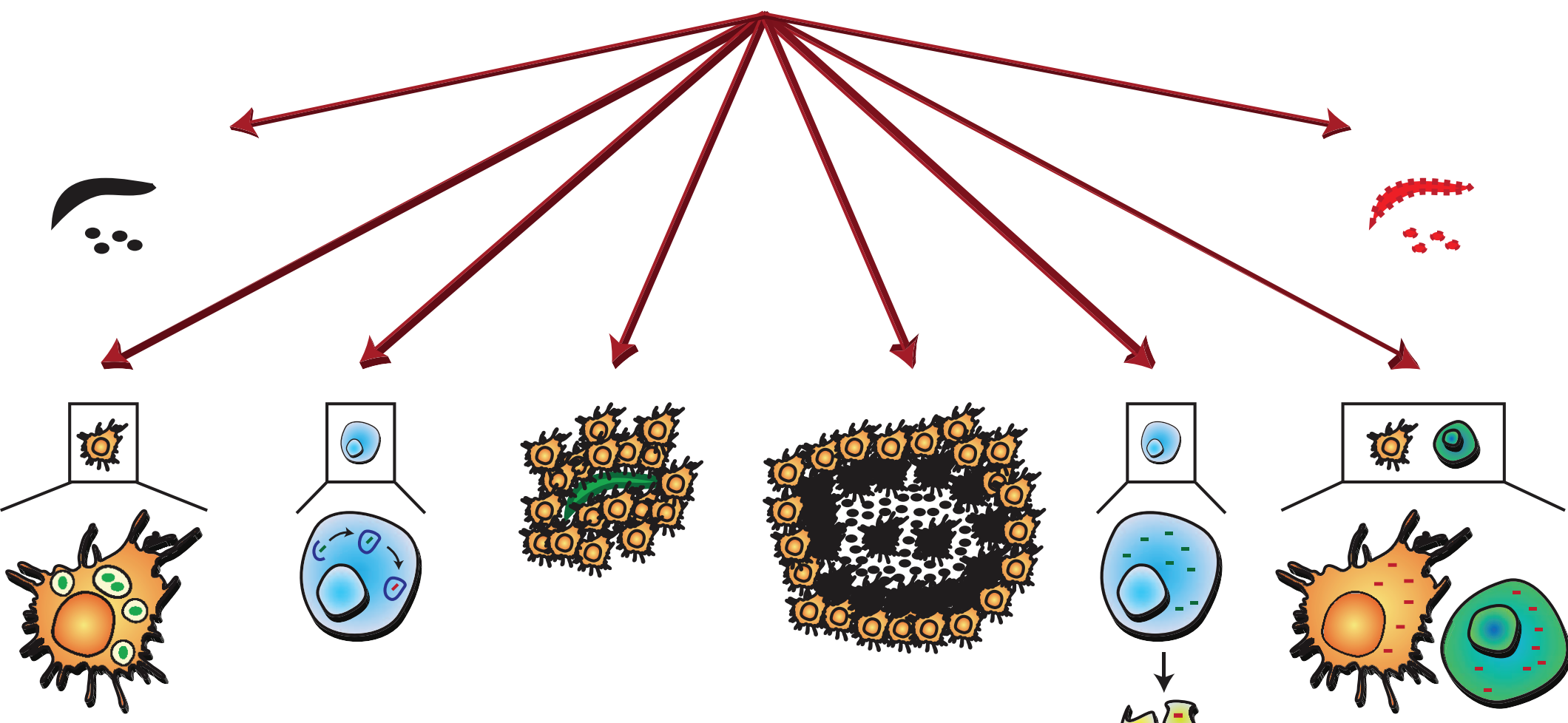


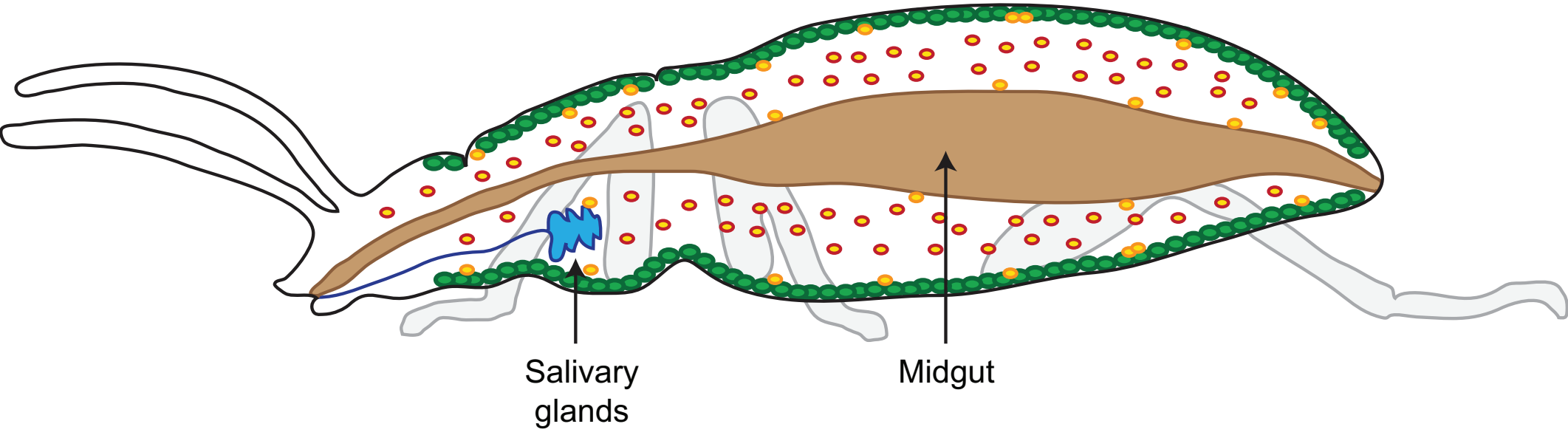

Legend: $\quad \begin{gathered}\text { Circulating } \\ \text { Hemocytes }\end{gathered} \quad \begin{gathered}\text { Sessile } \\ \text { Hemocytes }\end{gathered}$ ○ Fat body $\quad$ Anterior $\frac{\text { Posterior }}{\text { Ventral }}$




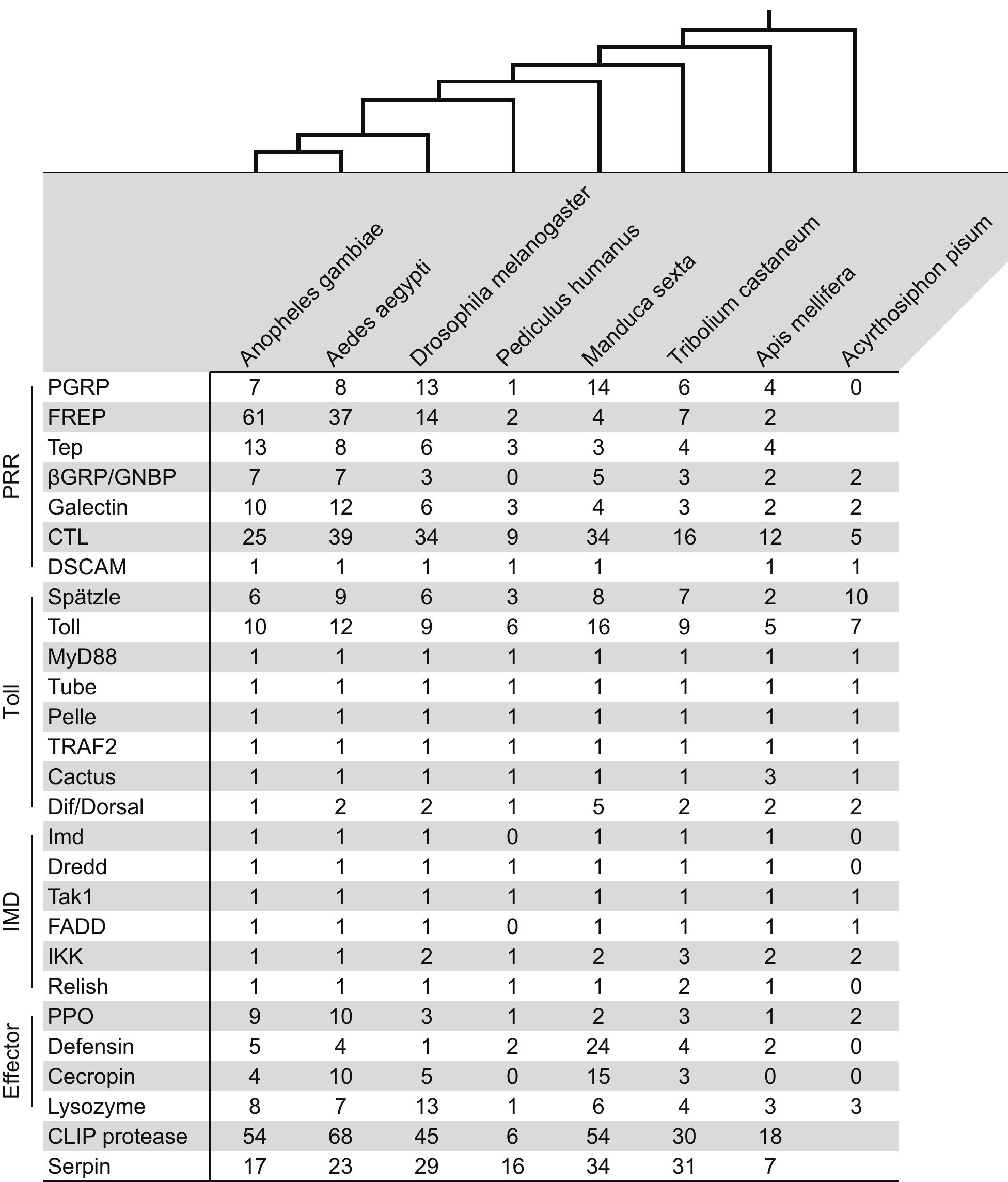




\section{Toll \\ Pathway}

Spätlze

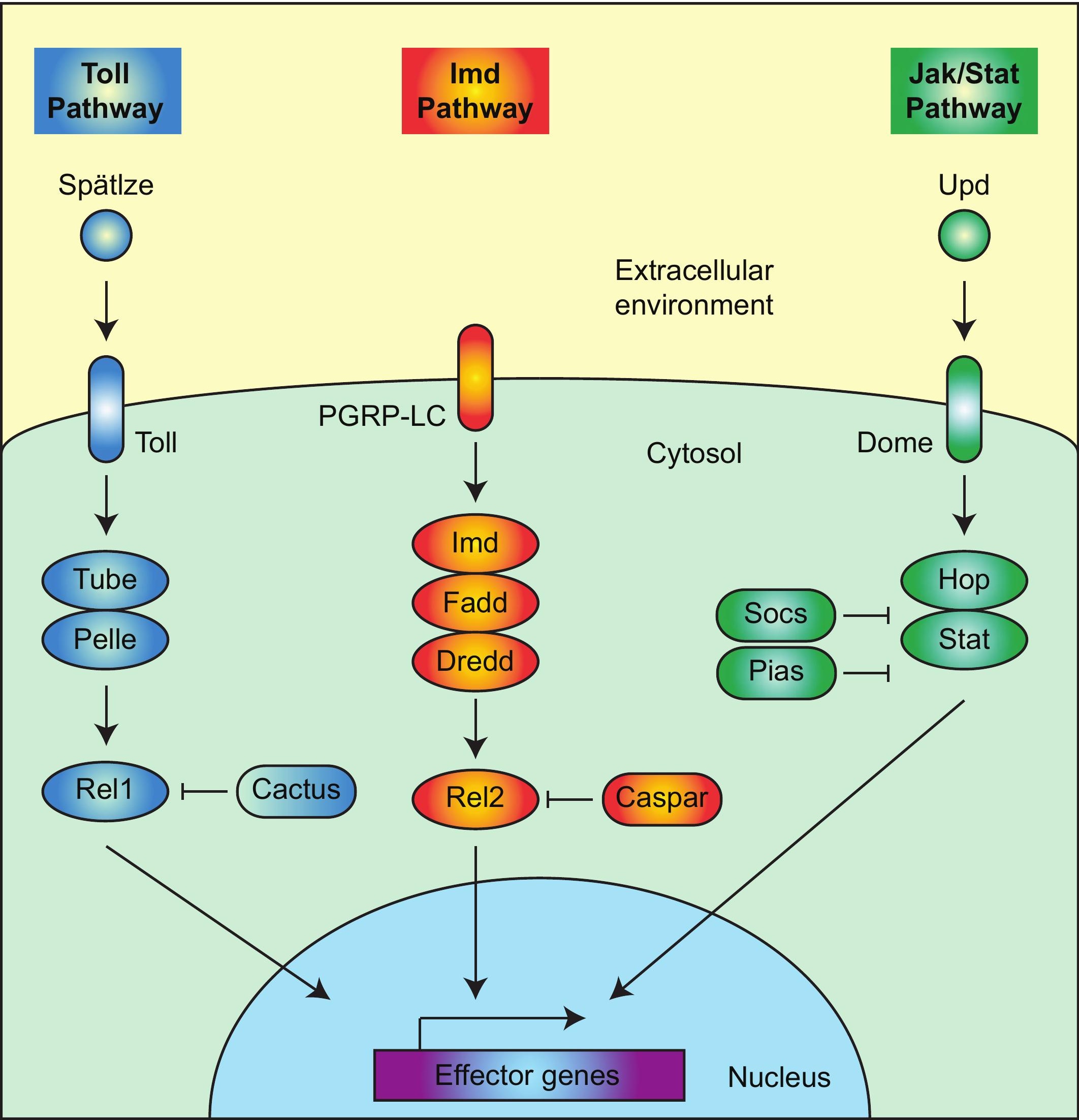

Jak/Stat

Pathway

Upd

Imd
Pathway

Extracellular

environment

Dome

Hop

Stat 


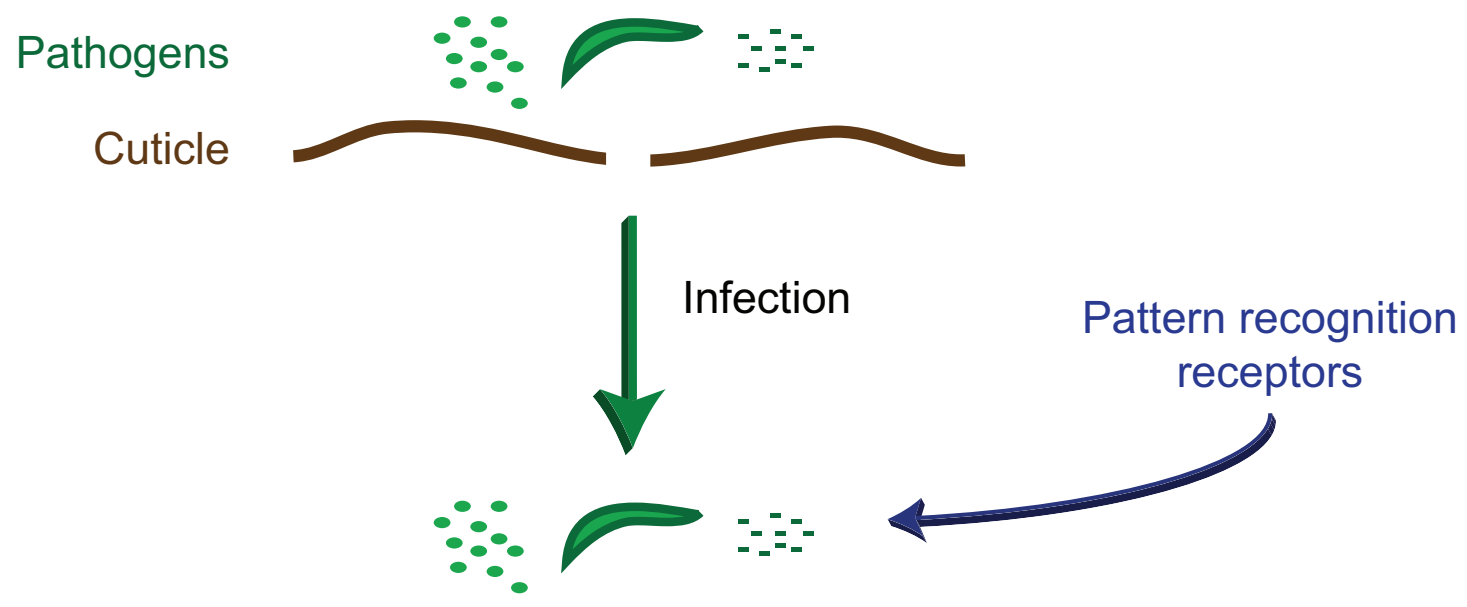

Melanization
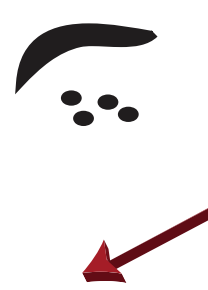

$\mathrm{Pr}$

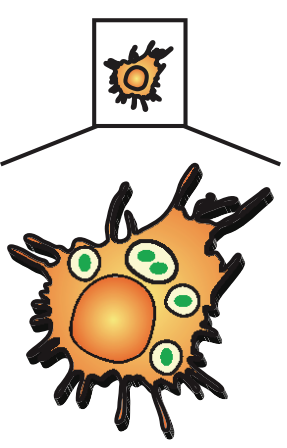

Autophagy Encapsulation
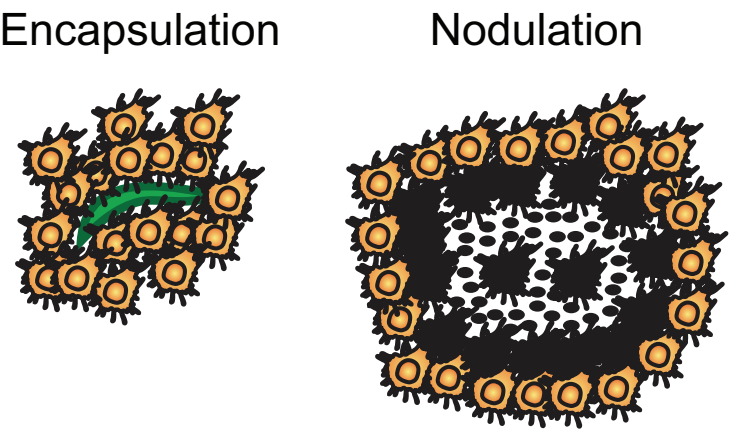

Apoptosis

Lysis
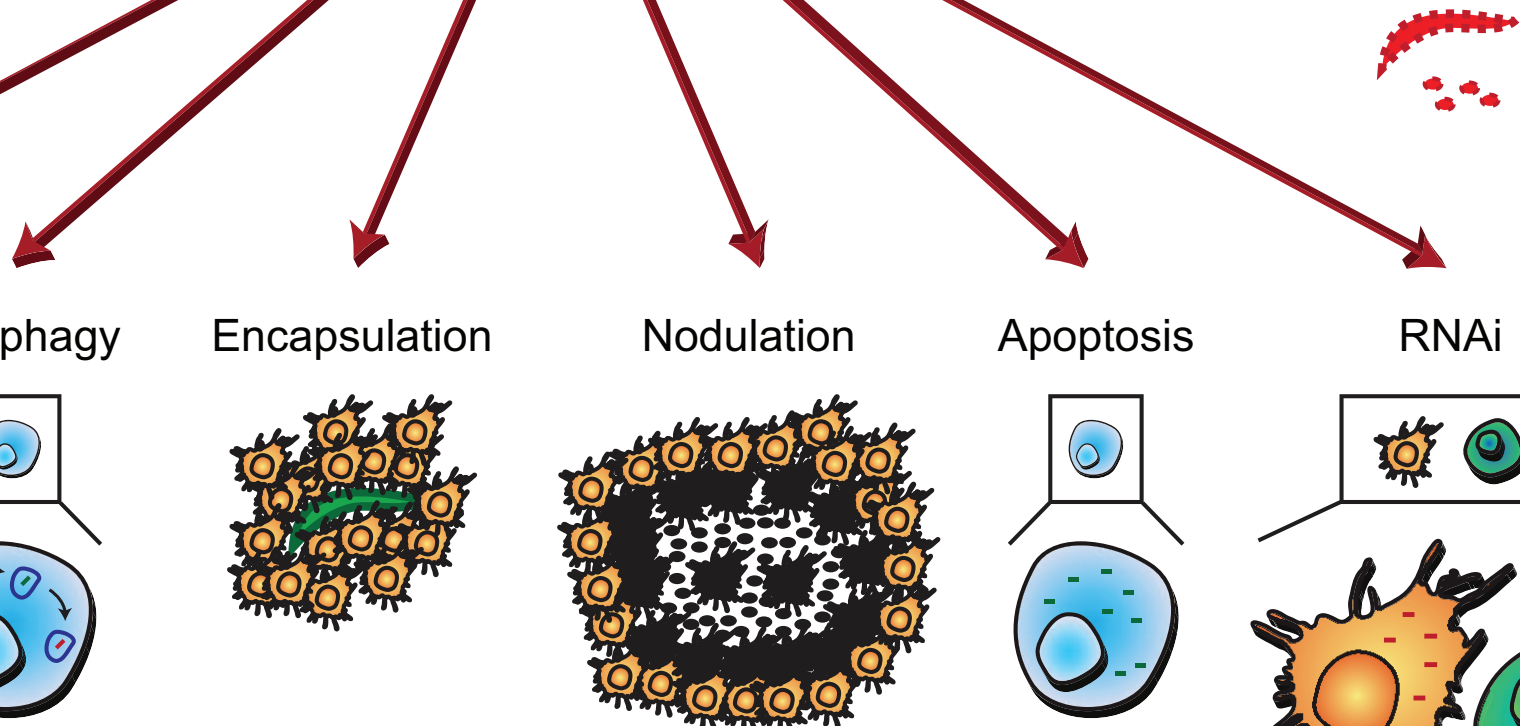

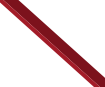
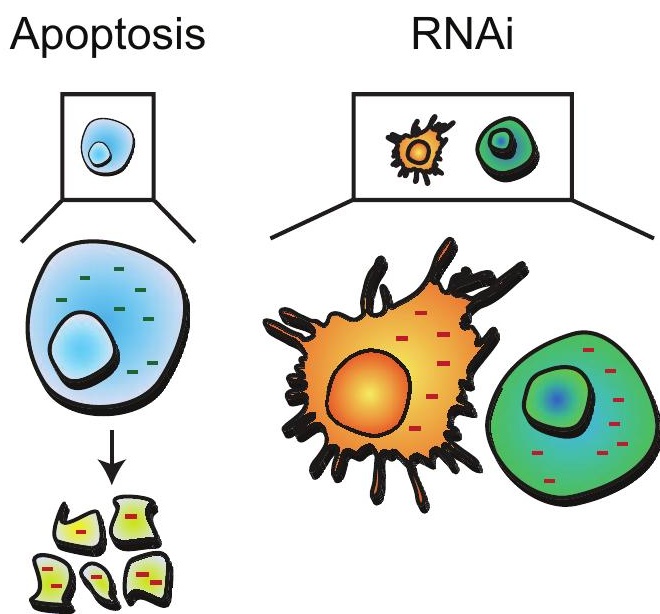
Pathogen recognition by PRRs

(e.g., $\beta$ GRPs, CTLs, GNBPs)

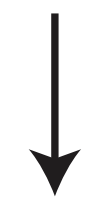

\section{Serine protease cascade}
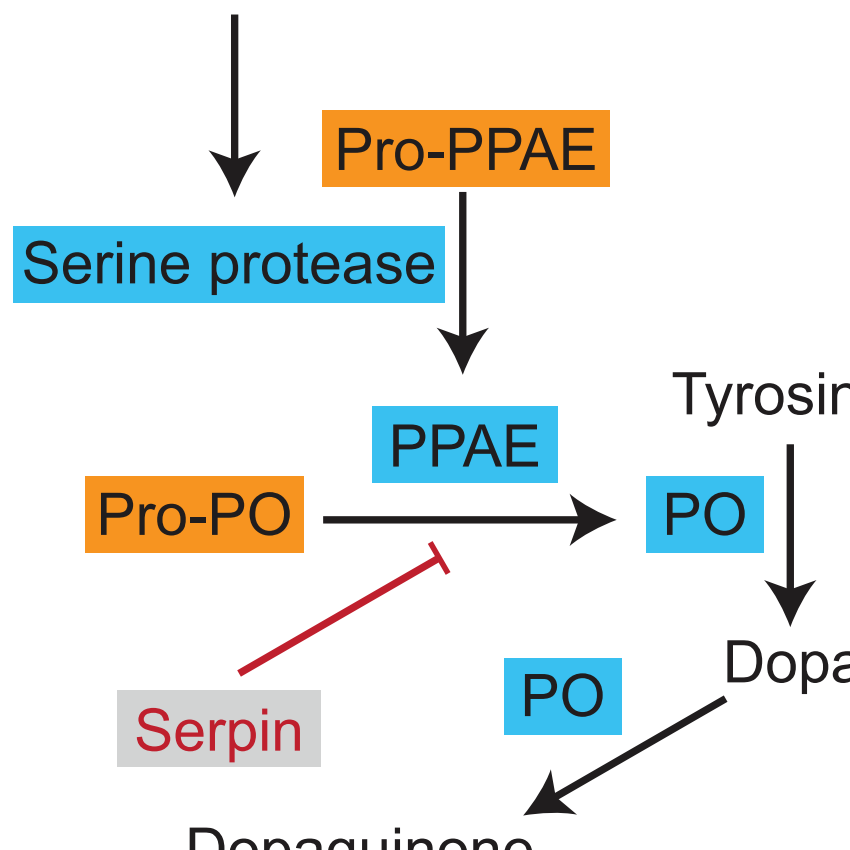

Dopaquinone

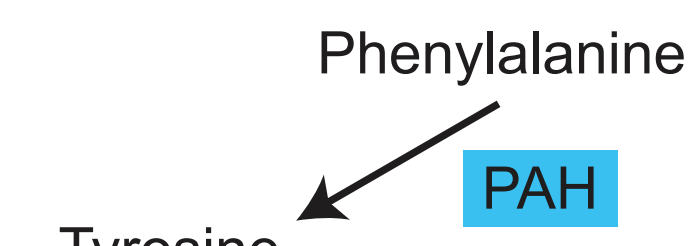

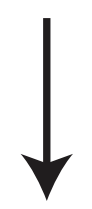

Dopachrome

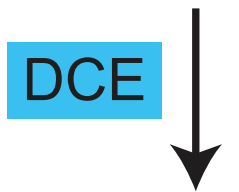

5,6-dihydroxyindole

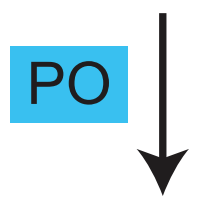

Indole-5,6-quinone

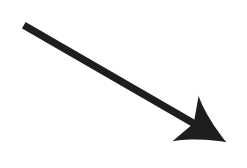

Hemolymph proteins

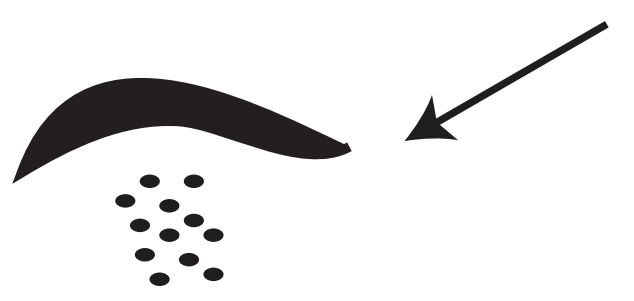

Melanization 

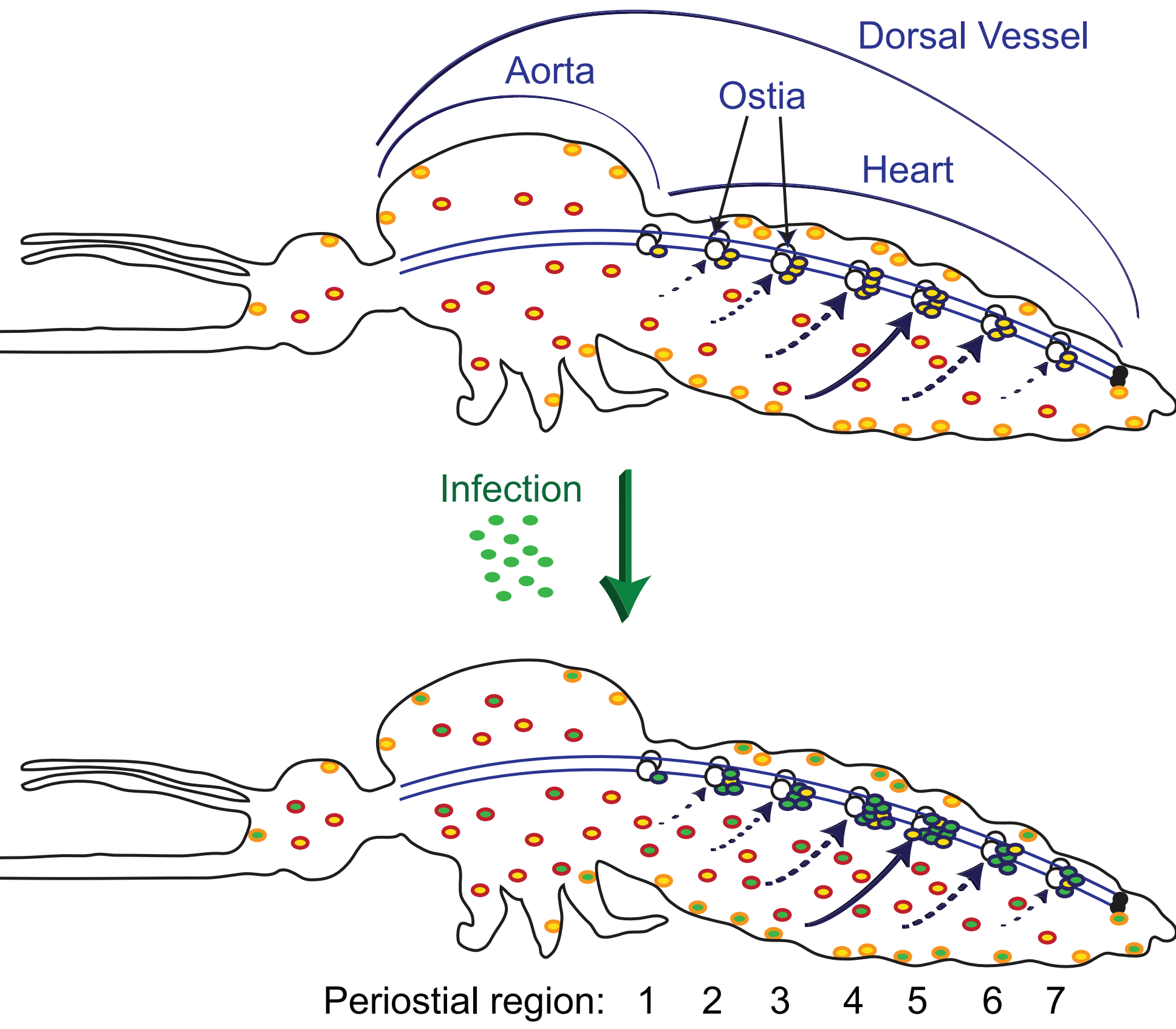

\section{Legend:}

Circulating $\left[\begin{array}{cc}\text { Sessile } \\ \text { Hemocytes }\end{array}\left[\begin{array}{l}\circ \text { Periostial } \\ \text { Hemocytes }\end{array}\right.\right.$ Hemocytes with
phagocytosed
pathogen $\left[\begin{array}{c}0 \\ 0\end{array}\right.$

Intensity of hemolymph flowing into the ostia (from low to high)

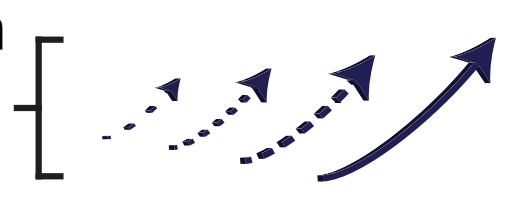

\author{
Dorsal \\ Anterior + Posterior \\ Ventral
}

